\title{
HOW DID THE WTC TOWERS COLLAPSE: A NEW THEORY
}

\author{
A.S. Usmani, Y.C.Chung and J.L.Torero \\ School of Engineering and Electronics, University of Edinburgh, \\ Edinburgh, EH9 3JN, UK
}

\begin{abstract}
This paper uses a finite element model to investigate the stability of the Twin-Towers of the World Trade Center, New York for a number of different fire scenarios. This investigation does not take into account the structural damage caused by the terrorist attack. However the fire scenarios included are based upon the likely fires that could have occurred as a result of the attack. A number of different explanations of how and why the Towers collapsed have appeared since the event. None of these however have adequately focused on the most important issue, namely 'what structural mechanisms led to the state which triggered the collapse'. Also, quite predictably, there are significant and fundamental differences in the explanations of the WTC collapses on offer so far. A complete consensus on any detailed explanation of the definitive causes and mechanisms of the collapse of these structures is well nigh impossible given the enormous uncertainties in key data (nature of the fires, damage to fire protection, heat transfer to structural members and nature and extent of structural damage for instance). There is however a consensus of sorts that the fires that burned in the structures after the attack had a big part to play in this collapse. The question is how big? Taking this to the extreme, this paper poses the hypothetical question, "had there been no structural damage would the structure have survived fires of a similar magnitude"?
\end{abstract}

A robust but simple computational and theoretical analysis has been carried out to answer this question. Robust because no gross assumptions have been made and varying important parameters over a wide range shows consistent behaviour supporting the overall conclusions. Simple because all results presented can be checked by any structural engineer either theoretically or using widely available structural analysis software tools. The results are illuminating and show that the structural system adopted for the Twin-Towers may have been unusually vulnerable to a major fire. The analysis results show a simple but unmistakable collapse mechanism that owes as much (or more) to the geometric thermal expansion effects as it does to the material effects of loss of strength and stiffness. The collapse mechanism discovered is a simple stability failure directly related to the effect of heating (fire). Additionally, the mechanism is not dependent upon failure of structural connections.

\section{KEYWORDS}

Structures in fire, WTC Towers, collapse mechanisms, stability of tall buildings

\section{INTRODUCTION}

Fires in buildings induce geometric (thermal expansion) and material effects (reduction in strength and stiffness) in structural elements. Computational modelling and analytical studies $[1,2]$ at Edinburgh University have shown that of these two competing effects in large frame structures, the former dominates the behaviour of the structure in the early stages while the latter becomes important near failure. In this paper structural behaviour is interpreted by analysing the typical structural responses to loading, namely, strains and stresses and more importantly their resultants (integrals), i.e. displacements and member forces. Research so far on composite steel frame structures in fire has shown that steel frame composite structures have a considerably more robust performance in fire than accounted for in design. This conclusion has been steadily gaining currency in the structural fire engineering profession over the last few decades. The main reason for this has been the absence of structural collapses even as a result of major fires in large composite frame structures. In UK the most 
important event was the Broadgate Phase 8 fire [3]. This eventually led BRE and British Steel (now Corus) to carry out 6 full scale fire tests on an 8-storey steel frame composite structure at the BRE Large Building Test Facility at Cardington (Bedforshire, UK) [4]. These tests consistently produced the expected robust behaviour for a range of compartments (small and moderately large) subjected to severe fires. To understand the mechanics governing this behaviour, a large concerted computational modelling exercise was carried out by University of Edinburgh, British Steel and Imperial College [1]. This project revealed in great detail the whole structure response to fire that produced the observed robust behaviour. This work has been reported extensively in many papers [5-7].

\section{Lessons from Cardington}

The details of modelling of the Cardington fire tests and subsequent interpretations of behaviour are too voluminous to present here, but considerable information can be downloaded from the web page given in [1]. Very briefly, this work revealed the following lessons for whole structure behaviour in fire:

- Restraint to thermal strain dominates the structural behaviour (in terms of internal forces and displacements)

- Relative to thermal strains, the contribution of conventional (gravity) loading is low (if no failure occurs)

- The results show low sensitivity to variations in strength and stiffness properties of steel, as thermal expansion swamps these effects

- At large deflections, tensile membrane action in the spans and compressive membrane action near the perimeter supports of floor slabs are observed

- Thermal strains produce a beneficial load-carrying shape for tensile membrane action in slabs, without large and damaging mechanical strains

- The load capacity is further enhanced by thermally induced pre-stressing in laterally restrained slabs and composite floor systems

- Local buckling (this is a misnomer as this is in fact 'local yielding' [8]) of the lower flanges of steel beams (acting compositely with the slab) occurs at relatively low steel temperatures (between $100^{\circ} \mathrm{C}$ to $200^{\circ} \mathrm{C}$ ) but this was not found to be a detrimental mechanism

A number of generally applicable fundamental principles of structural behaviour in fire were identified to be important as part of the modelling and analysis exercise [2] and proved invaluable in making sense of the complex computational results. These are:

1. Unrestrained thermal expansion caused by a rise in mean temperature of a structural member causes its ends to move apart. The thermal strain producing this expansion is

$$
\varepsilon_{T}=\alpha \Delta T
$$

where $\alpha$ is the coefficient of thermal expansion and $\Delta T$ is the average temperature increment.

2. Thermal expansion (or elongation) of a structural element in the presence of end restraints to lateral translation from the surrounding structure produces compression forces leading to yielding or buckling (depending upon the 'slenderness' of the structural element). For this to occur, neither the restraint stiffness nor the mean temperature rise has to be large. 
3. A thermal gradient over the depth of a simply supported structural element leads to 'thermal bowing' or curvature in the element,

$$
\phi=\alpha T_{, z}
$$

where $T_{z}$ is the average temperature gradient through the depth. The thermally induced curvature results in the pulling in of the ends in a simply supported beam. The reduction in distance between the ends can be written as a "contraction" strain,

$$
\varepsilon_{\phi}=1-\frac{\sin \frac{l \phi}{2}}{\frac{l \phi}{2}}
$$

where, $l$ is the length of the beam.

4. Restraint to end translation (while the rotations are free) in the presence of a through-depth thermal gradient (without any rise in mean temperature, therefore $\Delta T=0$ ) produces tensions in the beam which grow with growth in the thermal gradients.

5. Rigid restraint to end rotation, when $\Delta T=0$ and $T_{z}>0$, produces a hogging moment of $E I \phi$ over the whole length of the beam with no curvature. Finite rotational restraints produce combinations of hogging moments and curvature.

6. For a structural element restrained against end translation, but relatively free to rotate (as is often the case for many elements in real structures under real fires), combinations of thermal elongation and thermal bowing produce a whole range of internal forces, from large compressions to tensions. These internal forces however are always accompanied with large deflections toward the heated side of the member. If for the aforementioned structural element in a given fire the two effects of elongation and bowing are nearly equal, the internal forces (and therefore the damaging mechanical strains) in the element will be very small (this again is a common situation with many steel-concrete composite members). This is a direct result of the well known equation:

$$
\varepsilon_{\text {total }}=\varepsilon_{\text {thermal }}+\varepsilon_{\text {mechanical }}
$$

7. Compatibility of displacements in compartments with orthotropic stiffness and temperature distribution (for instance, steel only in one direction or compartments of high aspect ratio) influences the forces and displacements in orthogonal directions (such as tensions along the short span and compressions along the long span)

These principles, when set against the detailed results from the computational modelling of the Cardington Tests, provided excellent insights [8]. Further work has been underway towards developing new analysis and design methods [9-11], to fully exploit the new understanding developed in future analysis and design of structures for fire.

\section{Impact of 9/11}

While this remarkable progress in understanding the behaviour of structures in fire was achieved over the previous five years and hopes of great new strides in the future design of structures in fire were rising, the atrocity of 9/11 occurred. Initial reactions were quite predictably emotional and extreme, with some suggesting that skyscrapers should not be built using steel anymore. These initial reactions have thankfully given way to cold analysis and calculation and a desire to understand the exact nature of the mechanics that caused so many of the structures in the WTC complex to collapse.

\section{Analyses of the collapse}

One of the earliest significant attempts at explaining the Twin Tower collapses was by Bazant and 
Zhou, later published in [12]. This work restricts itself to explaining the progressive collapse of the whole structure caused by dynamic overloads from the falling superstructure as a rigid body, once the instability that made the superstructure mobile had already occurred. This analysis is interesting as it shows clearly that once this point is reached, the dynamic overloads will lead to complete collapse. However the bigger and much more important question is "what led to the instability that initiated the collapse in the first place". The briefly stated reason in the introduction section of this paper attributes this to creep buckling after prolonged heating of steel columns to temperatures of $800^{\circ} \mathrm{C}$ (and the loss of fire protection from the initial impact and explosion).

On the face of it this sounds credible, however the FEMA report [13] suggests that there could not have been an explosion (only small over-pressures) and that the temperatures could not have been that high over the whole fire affected area of the building at the same time. The report indicates that temperatures ranged from a high of $1100^{\circ} \mathrm{C}$ to a low of $400^{\circ} \mathrm{C}$, it also says that from photographic evidence there were a number of large local fires varying with both time and location. Therefore it is quite possible that when parts of the structure heated other parts may have cooled. The contribution of the aircraft fuel to the fire is moderate and limited to the initial minutes after impact leaving a fire limited by ventilation and fueled mainly by and average office building fuel load redistributed in a manner difficult to assess [14]. Empirical data on ventilation limited fires support the conclusion that average temperatures within the compartments would have remained within the range provided by the FEMA report [15] and could have led to energy release rates of the order of a gigawatt [14]. Numerical modelling using FDS validated this order of magnitude by comparing plume trajectory calculations with photographic images [14].

The hottest temperatures are expected to exist near the region of the openings where there is sufficient ventilation. It is very unlikely that the temperatures could have been that high in the interior of compartments of such a large aspect ratio (height to width) and the consequent resistance to ventilation it would create (because of the complex multi-cell flow patterns in such geometries). Internal damage of the core structure could have resulted in a significant increase in the oxidizer supply but numerical computations have shown that this would have also resulted in significant exterior flames. The video footage of the events shows dark smoke spewing from the openings caused by the initial impacts for the whole duration while the buildings remained erect. Thus, the authors favour the hypothesis that such enhanced ventilation did not exist [14].

The external columns had three of their faces open to atmosphere that in the absence of external flaming is inconsistent with high temperatures. Therefore one must conclude that even if there were areas of high temperature inside the building, it is quite likely that the columns did not heat significantly (even if they had lost fire protection).

The FEMA report also indicates that the despite the structural damage, the remaining columns retained significant load carrying capacity (as most of the external structure was designed to resist very high wind loading and in the absence of wind, would have provided considerable redundancy for gravity loads). The utilisation factor of for gravity loading is reported to be a very low $20 \%$ for exterior columns and a moderate $60 \%$ for the core columns. Considering these arguments (which clearly were not available to the authors at the time of the publication of their paper), the scenario of a large number of columns suffering creep buckling almost simultaneously is not credible. Structurally as well, a low temperature fire scenario makes more sense. This is because if the temperatures were to rise to $800^{\circ} \mathrm{C}$ over the whole compartment simultaneously with columns that had lost their fire protection, the buildings would not have survived for as long as they eventually did. This paper will show that there is a better explanation for initiation of the collapse which does not require very high temperatures.

Another notable cause of the collapse is provided by Quintiere et. al. [16] which is almost identical 
to the one tentatively put forward in the FEMA report [13]. This paper looks at a completely different explanation of the collapse. They have concentrated on the behaviour of the composite floor system and the supporting trusses. They correctly identify that the truss would undergo large deflections due to the effect of restrained thermal expansion. Beyond this point they conjecture that the large deflections would lead to tensile membrane action in the slab and the resultant tension would lead to connection failures and floor collapse, thus setting off a chain of progressive collapse. This theory is also improbable as it relies upon a large number of connection failures in a very short space of time to set off the floor collapses with sufficient kinetic energy. Furthermore, Cardington experiments have shown that connections remain under compression while the fires burn and the temperatures increase as a result of restrained thermal expansion (initially from steel and later from concrete expansion). They do snap in tension, but this occurs on cooling, when the fires have burnt out, which clearly was not the case for these buildings. The discussion of the attempts to analyse the WTC collapses indicate that although there has been considerable recent progress, there are too many counter-intuitive and subtle phenomena in the thermo-mechanical response of large frame structures to fires which are not well understood, even in the profession. Therefore, quite predictably, there are significant and fundamental differences in the explanations of the WTC collapses on offer so far.

\section{The aim of this work}

Although the Twin Towers themselves had sustained considerable structural damage, WTC 7 which had not, also collapsed (being the first recorded case of the collapse of such a structure entirely because of fire). This poor response from composite steel frame structures is not in accordance with the findings of Cardington [1]. All of the conclusions reached in analysing the Cardington experiments were reinforced by considerable theoretical/computational analysis, thus this work chooses to make use of the same principles and analysis that provided such a comprehensive explanation of the Cardington tests to explain the collapses in the WTC complex.

Given the magnitude of this task, this paper focuses on WTC $1 \& 2$ and seeks a more plausible explanation of the collapse of these structures. The emphasis will not be on comparative details between the computations and actual events, as such an emphasis will significantly complicate the task and perhaps also obfuscate the main issue. For this purpose, we have limited our investigation to a simple 2D model of the structure and to assess a range of fire scenarios (from severe to mild) that will cover the range of the plausible fires for WTC $1 \& 2$. Any effect of damage will be ignored. The aim of the investigation is not to predict the exact sequence of failure of the two Towers or to predict the failure times (as in [16]. The main purpose of this work is to find out if the structural system of the two Towers had an unusual vulnerability to large fires. Therefore a hypothetical failure mechanism is proposed (based on our understanding of the structure and its likely behaviour) and the model tested to see if the mechanism would actually occur for a range of fires. It will hopefully be seen later that the results produce a very credible scenario of collapse, which does not depend upon any gross assumptions about the fire or failure of connections or even structural damage. A clean stability failure mechanism is clearly indicated by a simple computational analysis. Not only this, the analysis is entirely consistent with the fundamental principles developed during the Cardington work [2]. The following sections report in reasonable detail the various steps of the analysis undertaken

\section{HYPOTHESIS}

The work began with the hypothesis graphically illustrated in Figures 1 and 2. Figure 1 shows a frame with external and internal columns connected by a long-span composite truss floor system (the internal columns are part of the building core and the external columns represent the closely spaced tubular columns of the WTC Towers). Figure 1 also shows the classical buckling collapse mechanism of the external columns under overloads in absence of any thermal effects (assuming that the trusscolumn connections are pins). For this mechanism to occur in the manner shown, it is necessary that 
the composite floor system has sufficient axial stiffness to be able to provide a minimum restraint to the column [17]. This restraint stiffness allows us to represent the whole system as a column laterally supported by translational springs (also shown in Figure 1). Given that sufficient stiffness is available in the springs, the classical Euler buckling mechanism will be as shown in Figure 1.

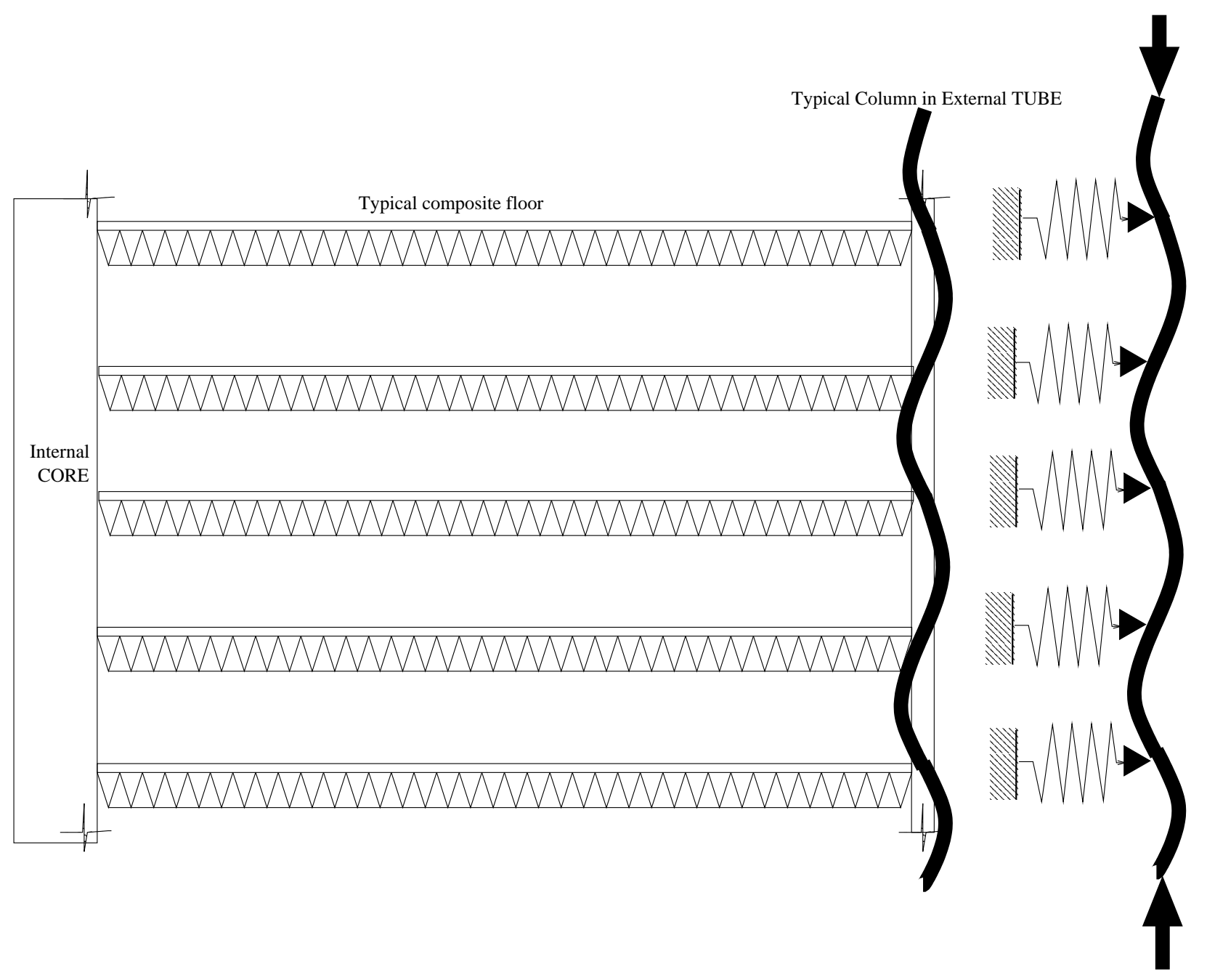

Figure 1: Classical buckling of columns in a multi-storey frame with sufficient lateral restraint

Now consider that for some reason the spring stiffnesses are reduced. One way this could occur would be if there was fire on one or more of the floors connecting the external and internal columns. A patently obvious reason for this is that if the fire burnt for long enough, it would eventually soften the steel trusses supporting the floors. Once the steel stiffness (modulus) reduces sufficiently, the axial stiffness demand for lateral support to the columns will no longer be available. This material softening effect would have occurred to varying degrees depending upon the fire and fire protection applied to the steel truss (assuming it had not been dislodged by the event that caused the fire). There is however another not so obvious reason for the loss of axial stiffness that does not depend so much on the level of steel fire protection. This effect is much more damaging to the stability of the overall structure than the previous one. It comes from the very first two principles of behaviour outlined in the previous section and is essentially a geometric effect. Note that the floor truss system is very long and quite slender and not really designed for in plane forces (membrane or axial compression). Initially the floor system may expand (for multiple floor fires thermal expansion will dominate over bowing as the 


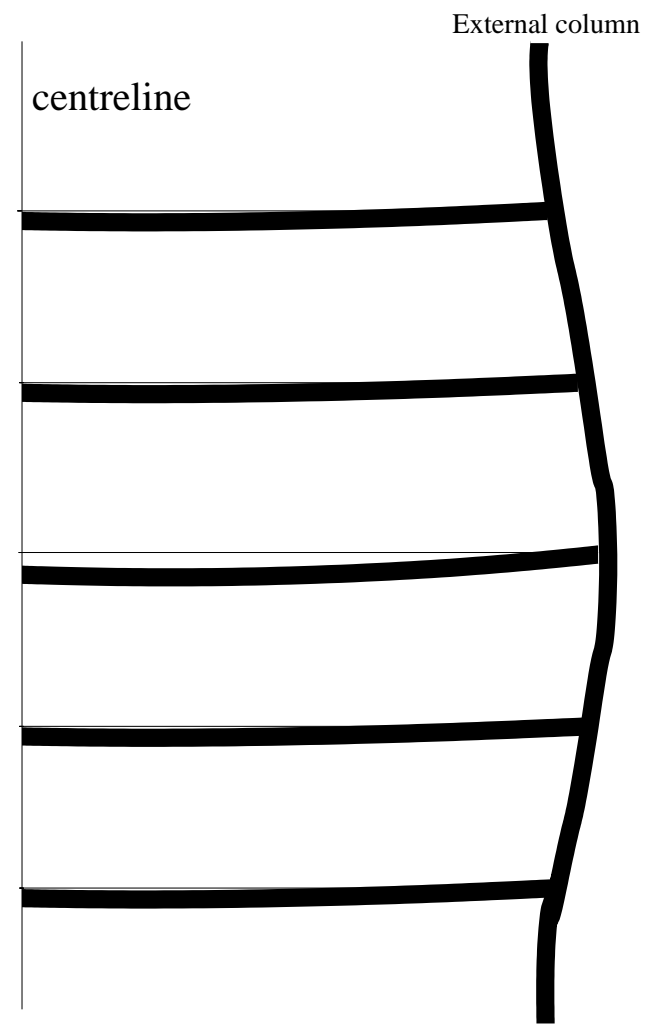

Initial thermal expansion (and thermal bowing) Columns pushed out as thermal expansion dominates

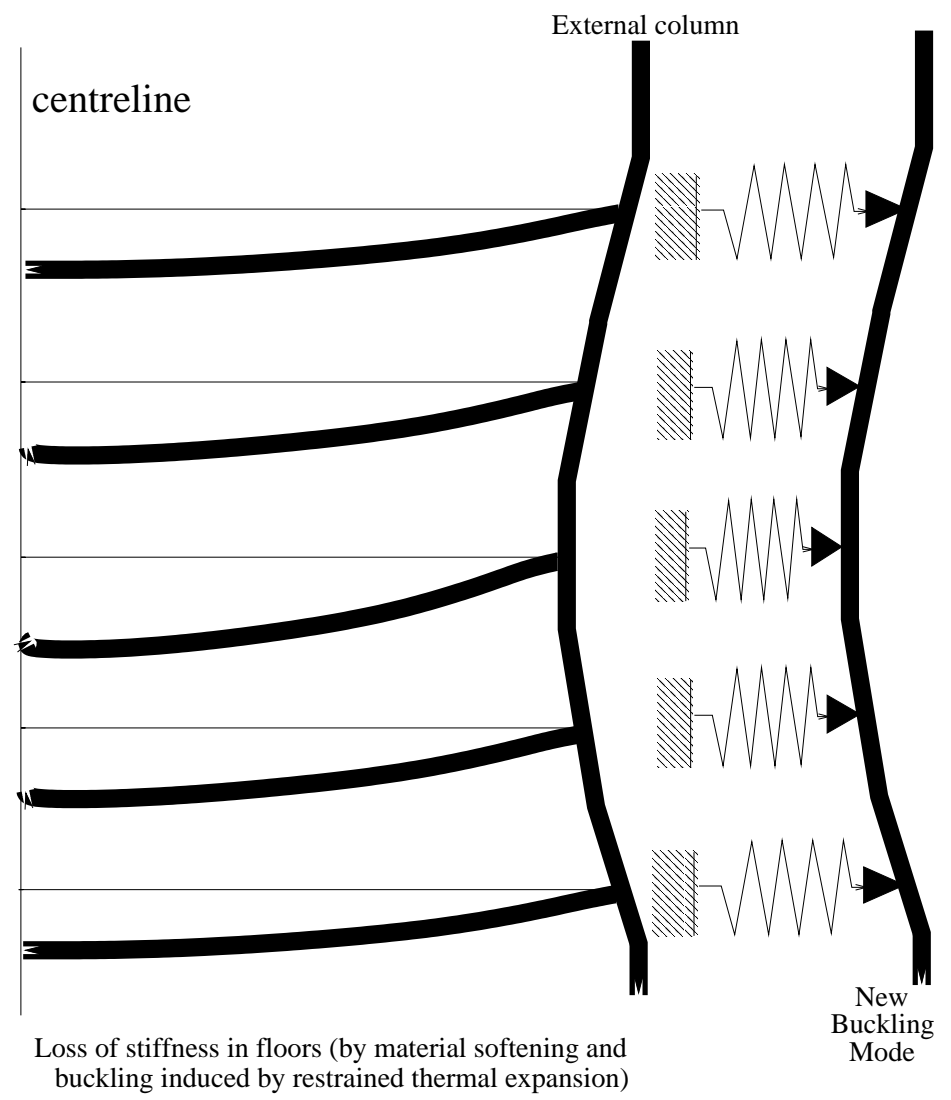

Figure 2: Classical buckling of columns in a multi-storey frame with reduced lateral restraint 
floor is heated from top and bottom) resulting in the pushing out of the external columns. Eventually the increasing membrane compressions from restrained thermal expansion and the high slenderness of the floor will lead to buckling of the floor and further increase in deflections. The significant change in the geometric shape of the floor system will lead to further reduction in axial capacity, leading to a rapid loss of lateral restraint to the column. If the fire has affected several floors, this loss of restraint will allow a much smaller load to buckle the external columns in a different buckling mode as shown in Figure 2.

A computational and analytical investigation has been carried out to test the hypothesis outlined above and determine possible collapse mechanisms for the World Trade Center Towers when subjected to a large fire. This investigation ignores the structural damage to the Towers as a result of the aircraft impacts and analyses a simple model of the WTC Towers for the effect of fire alone. The fire scenarios considered consist of a set of credible temperature distributions deduced by the authors (from other published work and their own investigations) and include a wide range of maximum fire temperatures. Structural effects of Single and multiple floor fires are analysed.

\section{COMPUTATIONAL MODEL}

The computational model chosen is a typical 2D slice of the Twin-Tower structure (as shown in the plan of the building in Figure 3). The height considered includes 12 floors around the impact level in the North Tower.

\section{Structural model}

It is assumed that the columns in the core region of the building would be relatively cool and that collapse would initiate at the external columns. Furthermore as the floor system is likely to be laterally restrained by the floor system in the core, therefore all translations of the composite trusses and concrete slab at the core end are restrained (rotation remains free). This is a reasonable assumption and simplifies the model considerably. The composite floor is pinned to the external columns at the other end. Figure 10 shows a schematic of the model. Typical dimensions of all members that make up the model (the truss components, concrete deck slab and the external column) are shown in Figure 4 [13]. The concrete deck slab is modelled to act compositely with the truss. The truss top and bottom chord were made of two angles back to back. An equivalent rectangular section is used in the model based on Figure 2.9 of the FEMA Report [13]. Figure 5 shows the finite element mesh of the model. The columns are modelled using 2D linear Timoshenko beam-column elements, and so were the concrete slab and the top and bottom chords of the truss. The concrete slab elements and the top chord elements were rigidly connected to model the composite behaviour using multiple point constraints. The diagonal elements of the truss were modelled using 2D axial elements. Only one linear axial element was used to model one truss diagonal, to enable the analysis times for the very large number of analyses carried out to be relatively small. As this was a large displacement non-linear analysis, the lack of sufficient nodes within the truss diagonals would enable them to remain much stiffer than actually would have been possible and would have over-estimated the structures capacity. The top and bottom chords however had sufficient nodes that could displace into the appropriate buckling modes. The use of stiffer diagonals also allowed the analysis to be carried considerably further into the post-failure regime. Temperature dependent material properties for steel (stress-strain curves and coefficient of thermal expansion) were taken from Eurocode 3 [18]. For the post-elastic behaviour of the concrete slab a Drucker-Prager model was used. The analyses were carried out using the commercial finite element software package ABAQUS.

Loading has been applied based on the approximate numbers mentioned in the FEMA Report [13]. A total load of approximately 1300 to 1400 tonnes is assumed to be uniformly distributed over the floors. The Floor loading area for the slice of structure modelled is assumed to be $2 \mathrm{~m}$ wide (consistent with the spacing of the double floor trusses). This gives a load of $8 \mathrm{kN} / \mathrm{m}$ on the horizontal elements. 


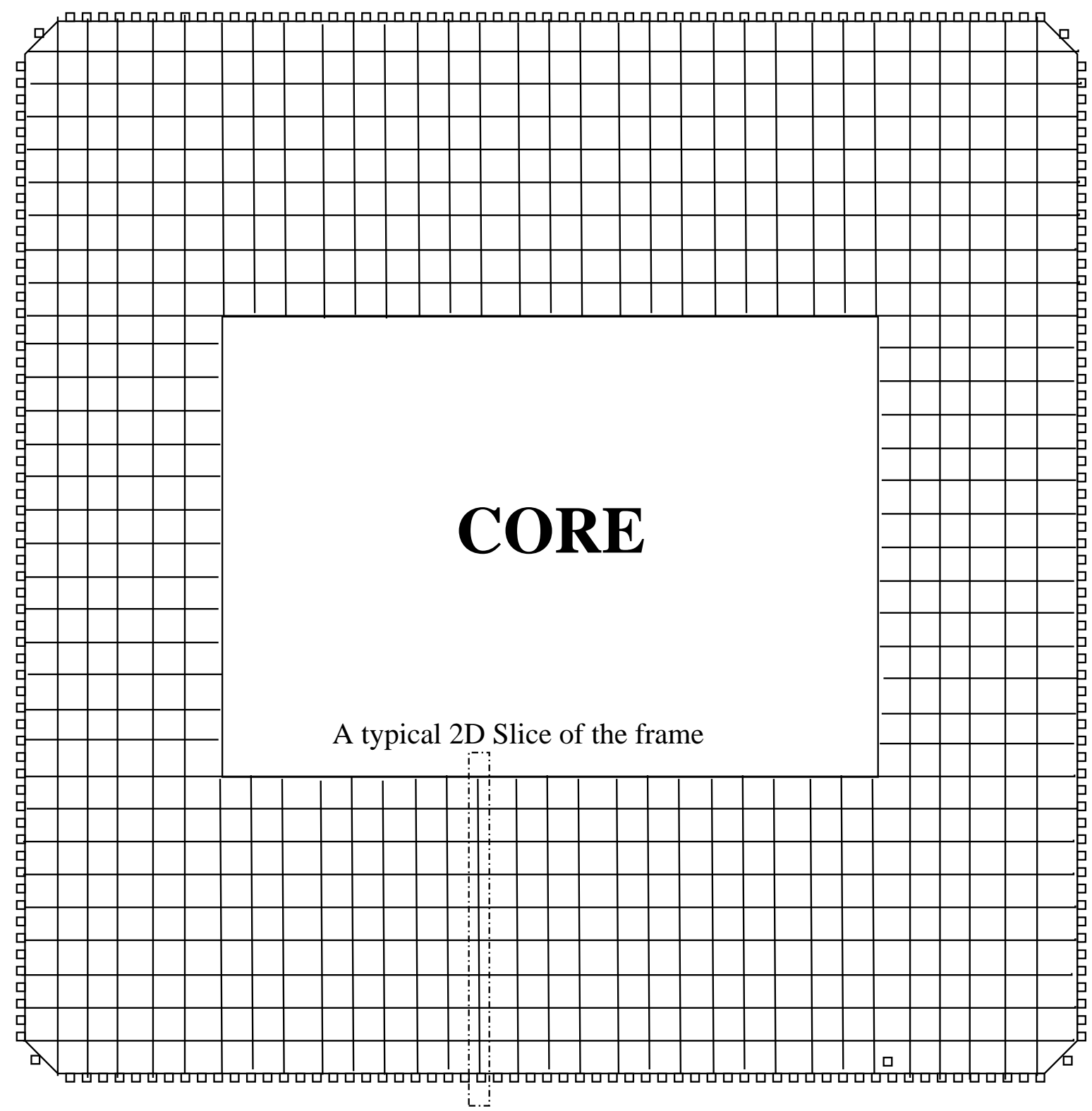

Figure 3: Plan view of a typical 2D slice of the building frame selected for analysis 
$40 \%$ of this load on eight storeys (representing the storeys above the model) is applied to the top of the columns. Furthermore, as the exterior columns are spaced at approximately $1 \mathrm{~m}$ centres, while the trusses framing into them are spaced at $2 \mathrm{~m}$ centres, two extreme cases are analysed. In the first case it is assumed that the column in the model has an area of cross-section equal to a single column (350 mm square hollow section with a plate thickness of $6 \mathrm{~mm}$ ). This is highly conservative as load will be redistributed to the neighbouring columns by the action of the spandrel beams connecting the columns. In the second case the cross-section area is doubled assuming full sharing of load between neighbouring columns.

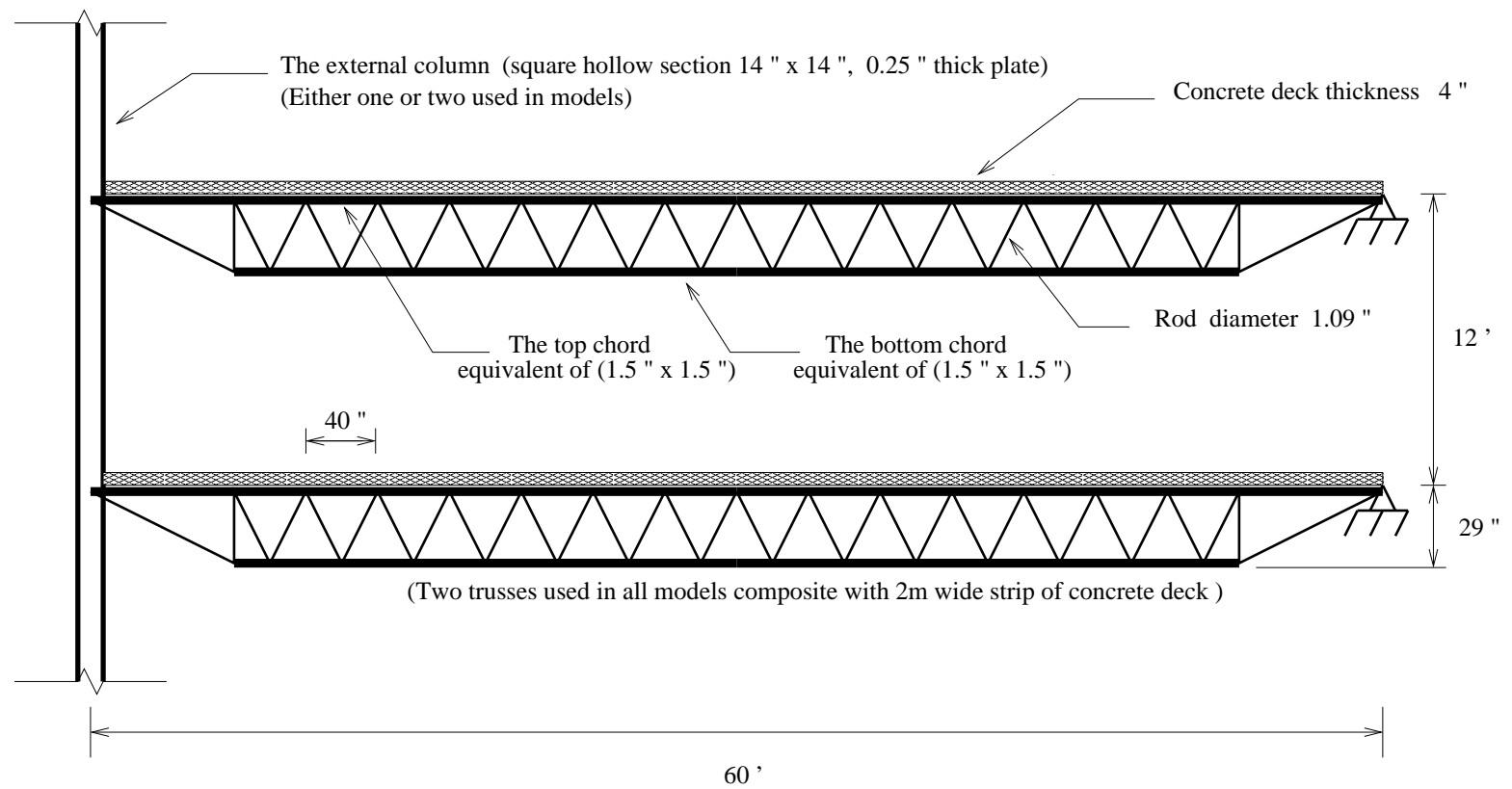

Figure 4: Typical model details and dimensions (shown in feet and inches)

\section{Fire scenarios}

The fire scenarios described in the introduction indicate a rapid onset of a generalized ventilation controlled fire that reaches moderate peak temperatures. The best representation of such a fire will be through the direct modelling of the heat exchange between gas and solid phases. Nevertheless, for this particular scenario these exchanges are highly uncertain, thus a gas phase temperature curve that incorporates the two main parameters of the problem (the heating rate and the maximum temperature) was considered adequate. A generalised exponential curve is chosen to represent the fire time-temperature relationship, and is given by:

$$
T(t)=T_{0}+\left(T_{\max }-T_{0}\right)\left(1-e^{-a t}\right)
$$

Where, $T_{\max }$ is maximum compartment temperature, $T_{0}$ is the initial or ambient temperature, and $a$ is an arbitrary 'rate of heating' parameter. A typical fire curve using Equation 1 is shown in Figure 7. The time variable is thus an artificial "time" that is generated to provide a sensitivity analysis to the current computations. These "temperature vs. time" curves are intended to represent colder/hotter fires or different levels of insulation. Nevertheless these artificial times should not be used for comparison with the actual time scales of the events of September 11th, 2001. The authors accept that issuing temperature time curves is inappropriate and they should be substituted by heat-flux vs. time curves corresponding to the specific fire. These temperatures are an arbitrary gas phase temperature assigned to the compartment from which a heat-flux is extracted via a convective-radiative heat transfer boundary condition. The different convective and radiative heat exchanges between surfaces, 


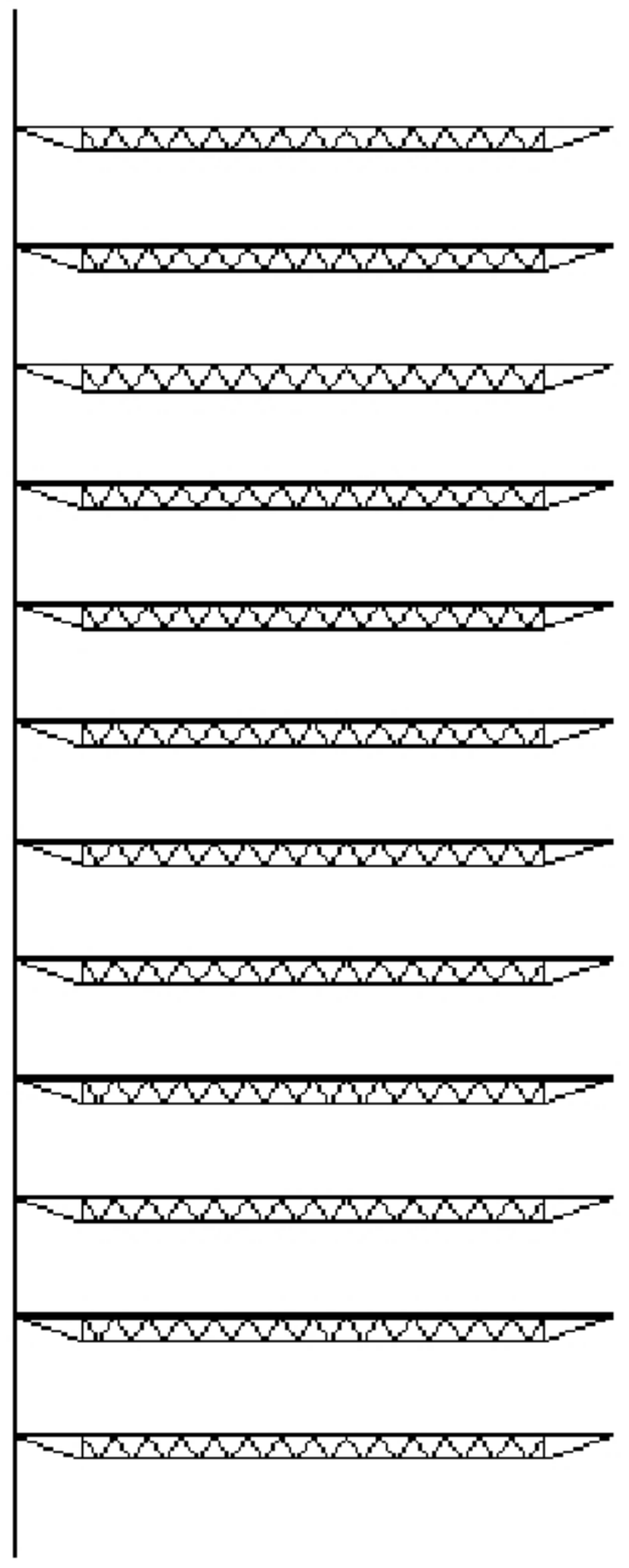

Figure 5: Finite element mesh of the 2D computational model 
fire and combustion products are not taken into account. The only justification for this approach is that by doing a parametric study a significant range of heat fluxes and heat-flux increase rates can be achieved. These will be expected to cover all the fire scenarios of interest.

The columns were assumed to be restricted to a maximum temperature of $400^{\circ} \mathrm{C}$, ramped linearly up from ambient for all the analyses regardless of the maximum compartment temperature assumed. In all the analyses where collapse occurred, the columns did not reach $400^{\circ} \mathrm{C}$ and therefore retained practically their full material strength. This is in view of the reasons discussed earlier suggesting that the external columns could remain relatively cool in a major fire. This is also a deliberately conservative assumption to show that the failure mechanism does not rely upon the reduced column capacity. The open web joist (or truss) temperatures were assumed to be the same as the compartment temperature as described above. For the composite deck slab, a 1D heat transfer analysis was carried out to determine the temperature distribution over the depth of the slab.

The gas phase temperature is then applied for a range of values of maximum temperature $\left(T_{\max }\right)$ and parameter $a$. The effect of internal ventilation due to core damage is addressed with various assumed spatial temperature distributions (as shown in Figure 6) along the length of the composite floor. These temperatures distributions are applied to fire scenarios encompassing one, two or three floors. The whole range of (over 100) analyses are shown in Table 1. In addition one further analysis was carried out for the particular case of $a$ tending to infinity as a bounding case corresponding to instantaneous attainment of the maximum temperature. This was done using fire scenario ' $\mathrm{C}$ ' for a 2-floor fire with a maximum temperature of $700^{\circ} \mathrm{C}$ and the model with stronger column.

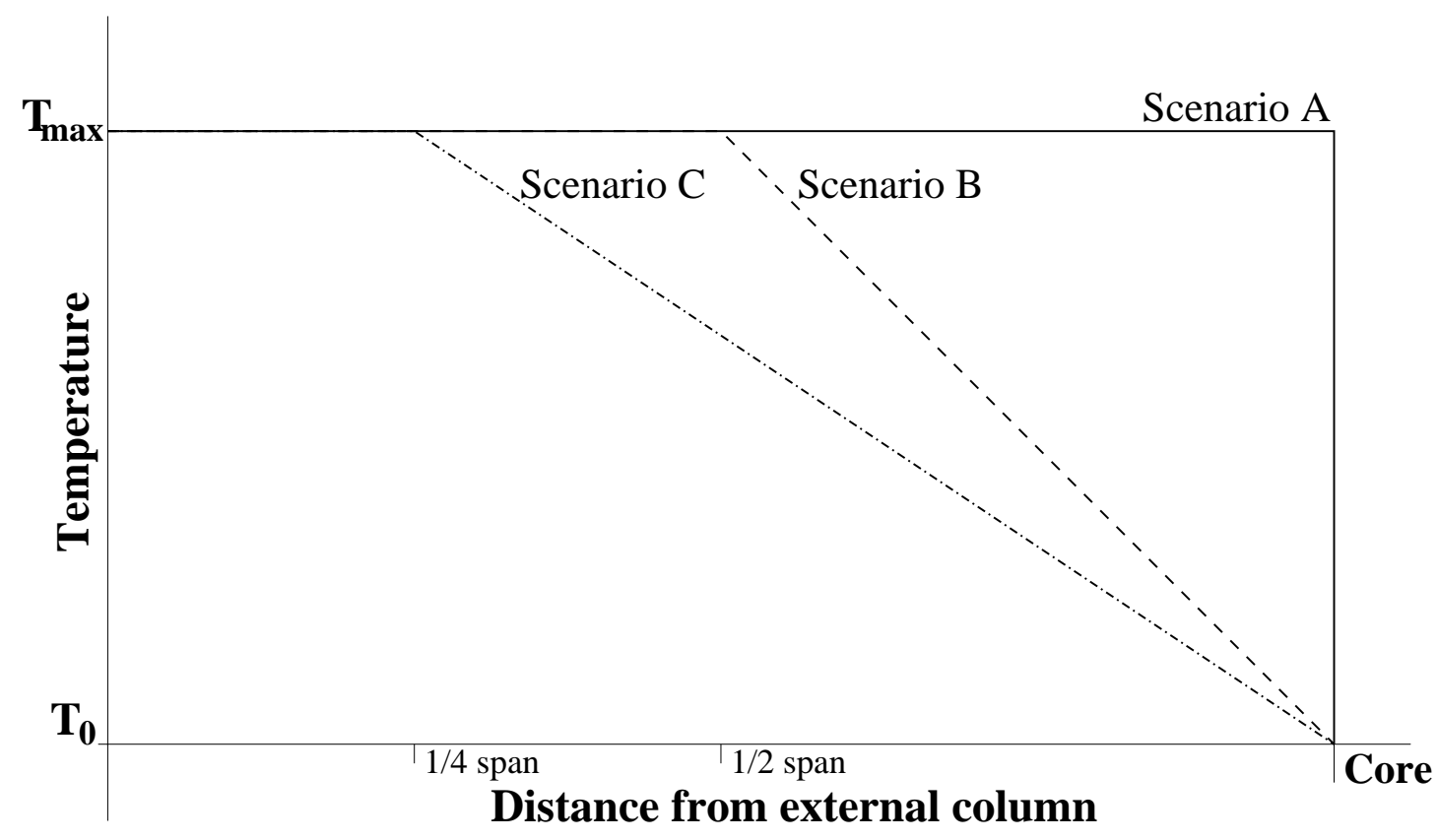

Figure 6: Assumed temperature distributions along the length of the floor

\section{ANALYSIS OF RESULTS}

Figure 8 shows an envelope of failure obtained from all the analyses carried out for the model with the assumption of a single column. The lines themselves and the area to the right or above the lines represents the scenarios for which the structure collapsed. For other scenarios, it came close to failure, however overall collapse did not occur. From Figure 8, it can be seen that even a single floor fire, if corresponding to scenarios A or B, collapses the structure at relatively modest compartment 
Fire time-temperature curves

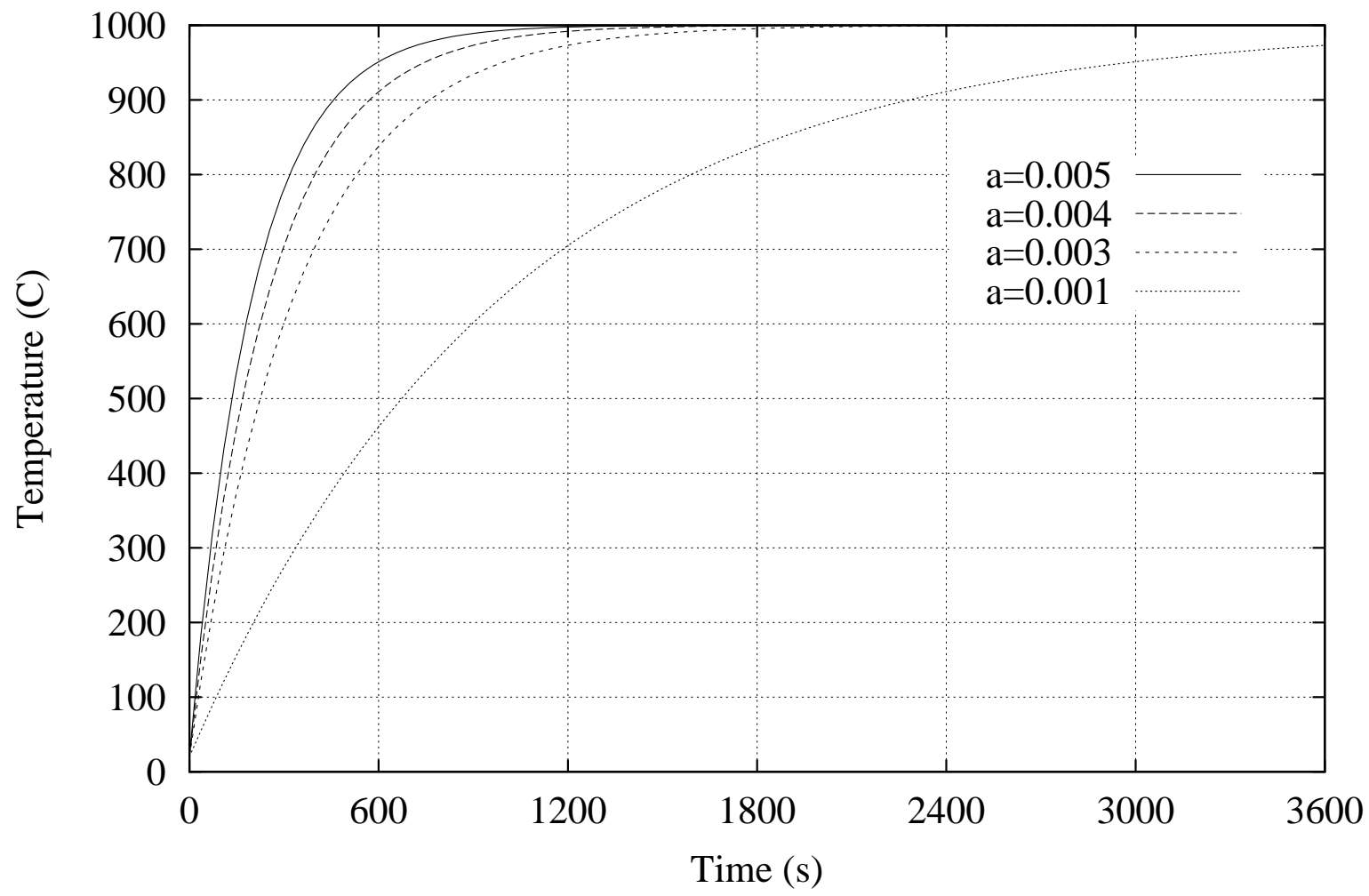

Figure 7: Temperature-time curves for different values of $a$ with $T_{\max }=1000^{\circ} \mathrm{C}, T_{0}=20^{\circ} \mathrm{C}$

\begin{tabular}{|c|c|c|c|c|}
\hline \multicolumn{2}{|c|}{$\begin{array}{c}\text { Fire } \\
\text { Scenario }\end{array}$} & \multicolumn{3}{c|}{$\begin{array}{c}\text { Number of floors under fire and } \\
\text { range of Maximum temperatures }\end{array}$} \\
\hline Tempr. distr. & $a$ & 1 & 2 & 3 \\
\hline A & 0.005 & $400^{\circ} \mathrm{C}-1000^{\circ} \mathrm{C}$ & $400^{\circ} \mathrm{C}-1000^{\circ} \mathrm{C}$ & $1000^{\circ} \mathrm{C}$ \\
\hline B & 0.005 & $400^{\circ} \mathrm{C}-1000^{\circ} \mathrm{C}$ & $400^{\circ} \mathrm{C}-1000^{\circ} \mathrm{C}$ & - \\
\hline $\mathrm{C}$ & 0.005 & $400^{\circ} \mathrm{C}-1000^{\circ} \mathrm{C}$ & $400^{\circ} \mathrm{C}-1000^{\circ} \mathrm{C}$ & - \\
\hline $\mathrm{C}$ & 0.004 & $400^{\circ} \mathrm{C}-1000^{\circ} \mathrm{C}$ & $400^{\circ} \mathrm{C}-1000^{\circ} \mathrm{C}$ & - \\
\hline $\mathrm{C}$ & 0.003 & $400^{\circ} \mathrm{C}-1000^{\circ} \mathrm{C}$ & $400^{\circ} \mathrm{C}-1000^{\circ} \mathrm{C}$ & - \\
\hline C & 0.001 & $400^{\circ} \mathrm{C}-1000^{\circ} \mathrm{C}$ & $400^{\circ} \mathrm{C}-1000^{\circ} \mathrm{C}$ & $400^{\circ} \mathrm{C}-1000^{\circ} \mathrm{C}$ \\
\hline
\end{tabular}

Table 1: The full range of fire scenarios for all analyses carried out 
temperatures of $600^{\circ} \mathrm{C}$ and $700^{\circ} \mathrm{C}$. At this point it is important to state that the word "collapse" does mean actual failure seen in the numerical model, which is an accelerating and irreversible downward displacement of the nodes connecting the column and the fire floors. The cases where the fire floor(s) buckle but the structure stabilises after this event have not been counted as a failure (such as the second specific analysis of the model with double column and 2 floor fire scenario $\mathrm{C}$ with $\mathrm{a}=0.005$ and $T_{\max }=700^{\circ} \mathrm{C}$, discussed below). The best indicator of collapse has been the rate of change of displacement (pseudo-velocity) against time plots (such as Figure 14).

It should be noted that the temperatures of the truss are assumed to be the same as the compartment temperature in the analysis. The column temperatures are ramped from ambient to $400^{\circ} \mathrm{C}$ over the whole period of the fire. The maximum temperature of $400^{\circ} \mathrm{C}$ was chosen for the columns on the basis of the video images that showed minimal external flaming (therefore in all of the analyses where collapse occurred the column temperatures were lower than $400^{\circ} \mathrm{C}$ ). For the concrete slab a total heat flux (convection and radiation) boundary condition is imposed and in-depth temperature distributions calculated as a function of time using a one-dimensional finite element heat transfer analysis (including the effect of water evaporation).

Fire scenario $\mathrm{C}$, which is perhaps the most realistic one, does not show failure for any single floor scenario, however it shows collapse to occur at a very low temperatures $\left(400^{\circ} \mathrm{C}\right)$ when two or more floors are involved. At such low temperatures, there is negligible loss of steel strength and the cause of failure is entirely because of instability created by geometric changes in the structure as a result of the thermal expansion. As these geometric structural stability phenomena are of the greatest interest here, we will attempt to explain this in considerable detail in discussing a few individual analyses. It

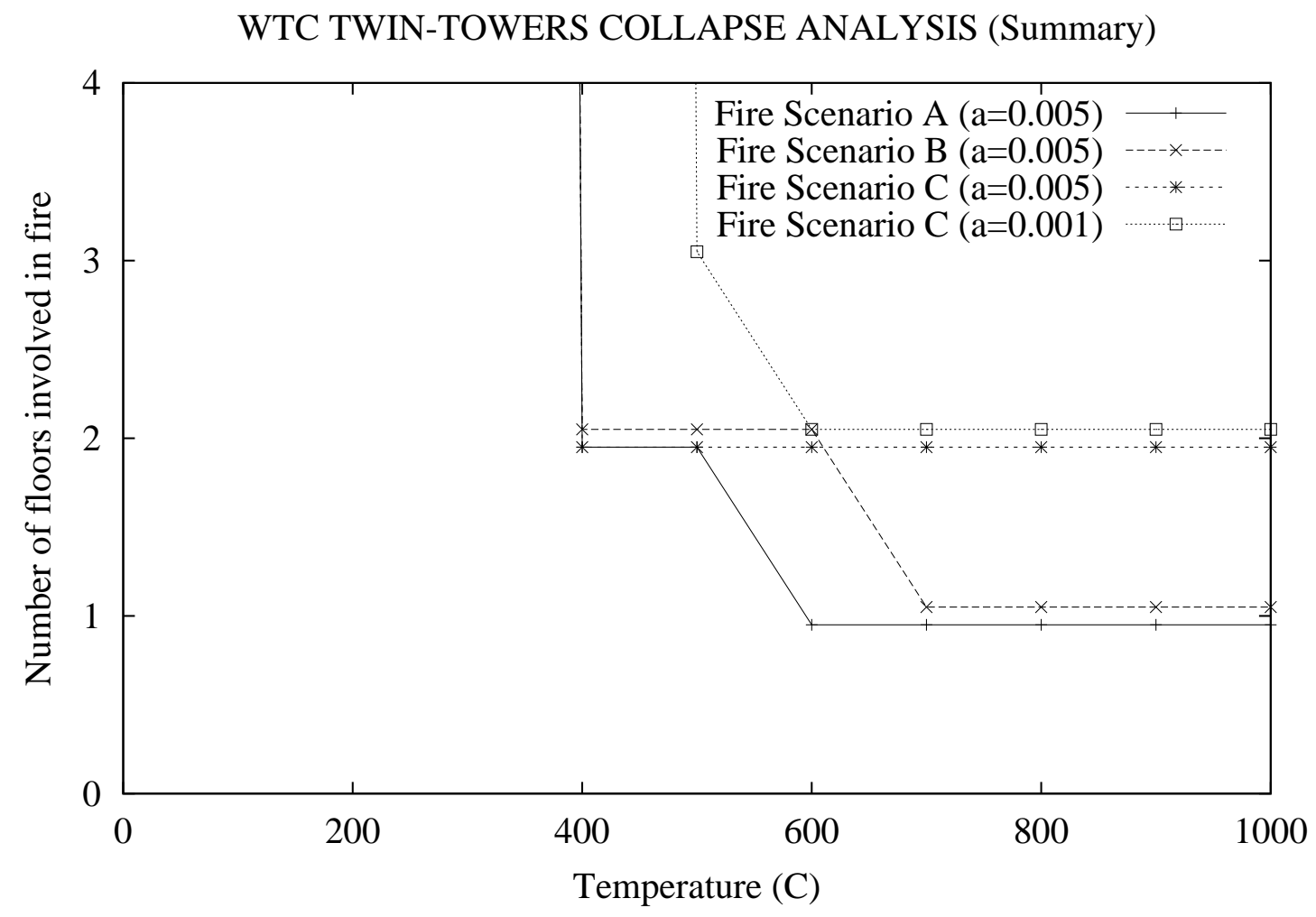

Figure 8: Failure envelope from all scenarios analysed for the single column model

is beyond the scope of this paper to discuss each of the over a hundred analyses carried out. This is not necessary either as all the analyses show primarily the same collapse mechanism. Therefore three analyses are chosen for detailed discussion in the following sub-sections. 
Model with a single column, 2-floor fire scenario C, $a=0.001, T_{\max }=600^{\circ} \mathrm{C}$

This scenario involves a slowly developing fire (consistent with some undamaged fire protection on the trusses) leading to a maximum compartment temperature of just under $600^{\circ} \mathrm{C}$. Figure 9 shows the time-temperature curve for the fire used for this analysis. This temperature is applied on two floors as shown in Figure 10. These floors are assumed to be located at the centre of impact in WTC 1 (96th floor, North Tower). The structural load applied to the top of the column in the model (node 1156 in Figure 10) is consistent with this location.

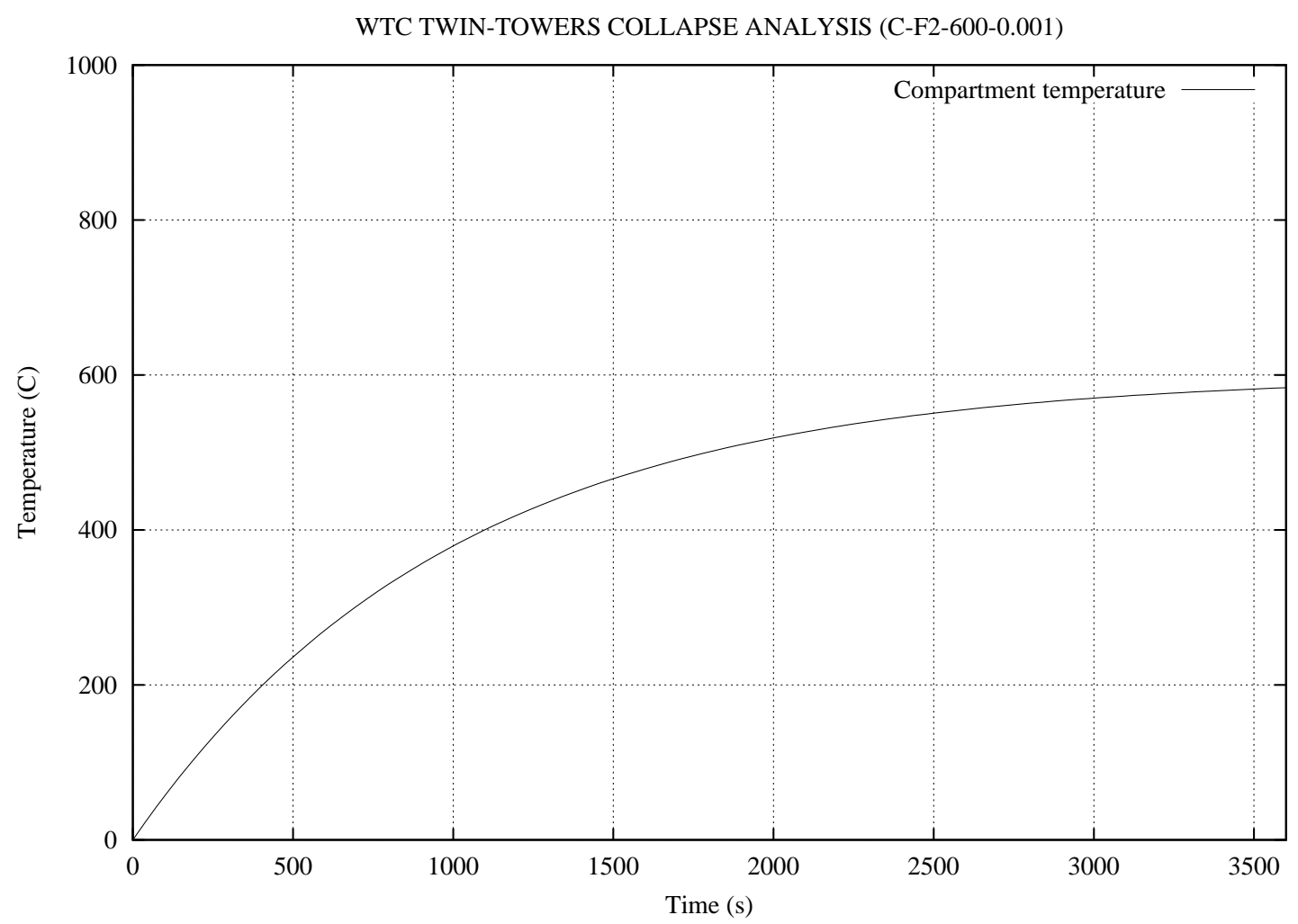

Figure 9: Compartment fire evolution

This fire is applied to two floors (as shown in Figure 10). Figures 11, 12 and 13 show the displacement variation at various locations in the model. These include the vertical deflections of the midspan of the main fire floor and the floors above and below it (node 51018, 61018 and 71018); column horizontal and vertical displacements at the fire floor (node 1072 in Figure 10); and column horizontal displacements two floors above and below the fire floor (nodes 1060, 1048, 1072, 1084 and 1096). Figure 11 shows that the displacement of the main fire floor and the floor above it are practically identical until 1700 seconds, beyond which all the deflections increase significantly and collapse occurs. There is however a difference in the temperature distribution in these two floors. The main fire floor is heated from both top and bottom and therefore is subject primarily to a mean temperature rise and negligible thermal gradients. The floor above is only heated from below and will therefore be subject to both, a mean temperature rise and a thermal gradient over the depth. The deflection of the floor below the main fire floor is quite low until collapse initiates as it is heated only from above (the steel truss is not affected).

Figure 12 shows the displacements of the column for the first 1500 seconds of analysis (pseudo-time, as this is not a dynamic analysis, and time is simply linked to the compartment temperature applied). Until approximately 1200 seconds the column expands outwards by about $15 \mathrm{~mm}$ at the junction with the main fire floor (where the floor is heated from two fires above and below and the greatest thermal 


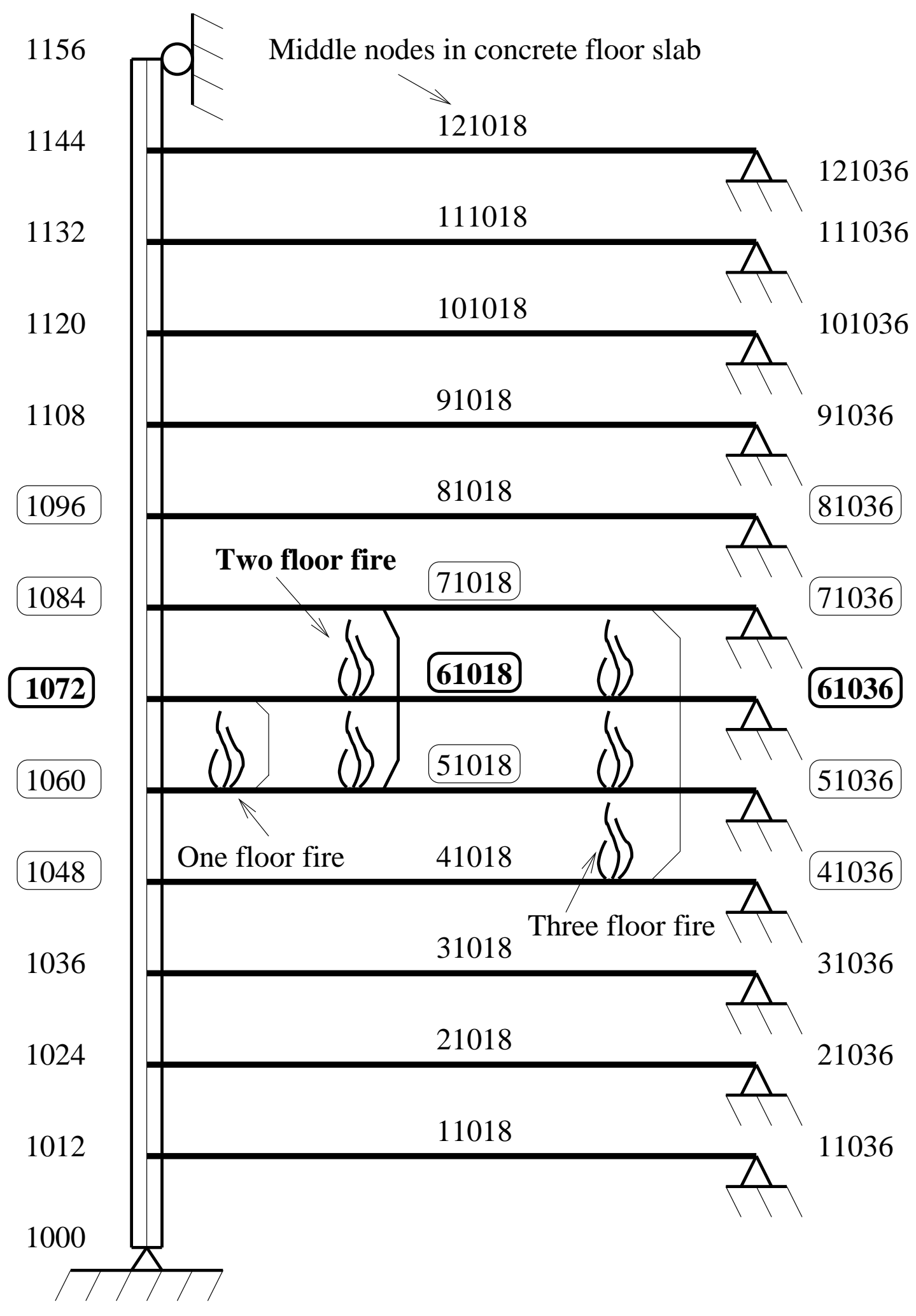

Figure 10: Location of nodes at which outputs are plotted (hottest floor nodes for 2-floor fire in bold) 


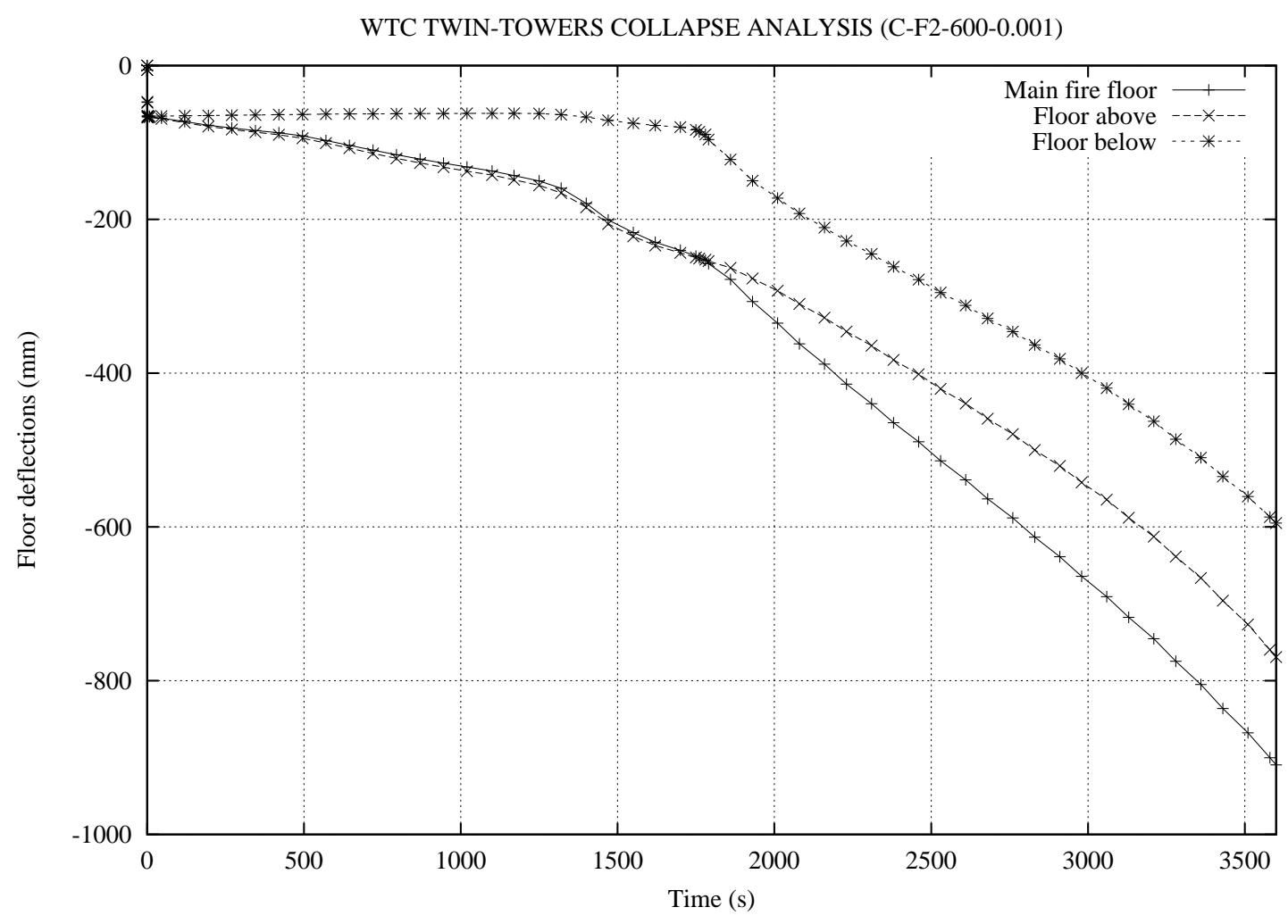

Figure 11: Floor deflections

expansion is generated). It may also be noticed that at the same time this joint is also moving slowly upward because of thermal expansion of the column itself. At 1200 seconds the outward expansion slows down and reverses. The rate of this reverse displacement increases and shoots past the original position after 1300 seconds.

Figure 13 shows all displacements begin to increase dramatically at approximately 1400 seconds. Lateral displacement of over $1 \mathrm{~m}$ is achieved in the column at the main fire floor level and approximately $700 \mathrm{~mm}$ at the floors above and below this level. There is relatively little displacement in the non-fire floors. The reasons for this behaviour will become apparent in subsequent discussion. The increased rate of downward displacement of the column and floor midspan also in the Figure, indicates the onset of overall collapse.

Figure 14 shows the rate of displacement with time (velocity) of the column at the junction with the main fire floor (at node 1072, Figure 10). Until roughly 1200 seconds, the velocity is negative, indicating outward movement of the column. Beyond this it becomes positive and considerable acceleration is apparent. As an aside, it may be noted that had this been a dynamic analysis this would create considerable inertial destabilising forces. However, a counter argument to this is that the mass of the structure could also have reduced the velocity in the first place. Therefore a dynamic analysis is desirable to understand this effect. Returning to the Figure 14, a deceleration is noticed around 1500 seconds which lasts until roughly 1700 seconds, beyond which collapse truly begins. The 'wiggles' in the curve are an indication of the difficulty the numerical algorithm is experiencing in finding an equilibrium position. The lower curve shows the column starting to accelerate downwards beyond 1800 seconds. Again the reason for this behaviour will become apparent with further analysis.

Clearly one of the purposes of the floors is to provide lateral support to the columns. Figure 15 shows the variation in the axial forces in the main fire floor and two floors above and below this. 


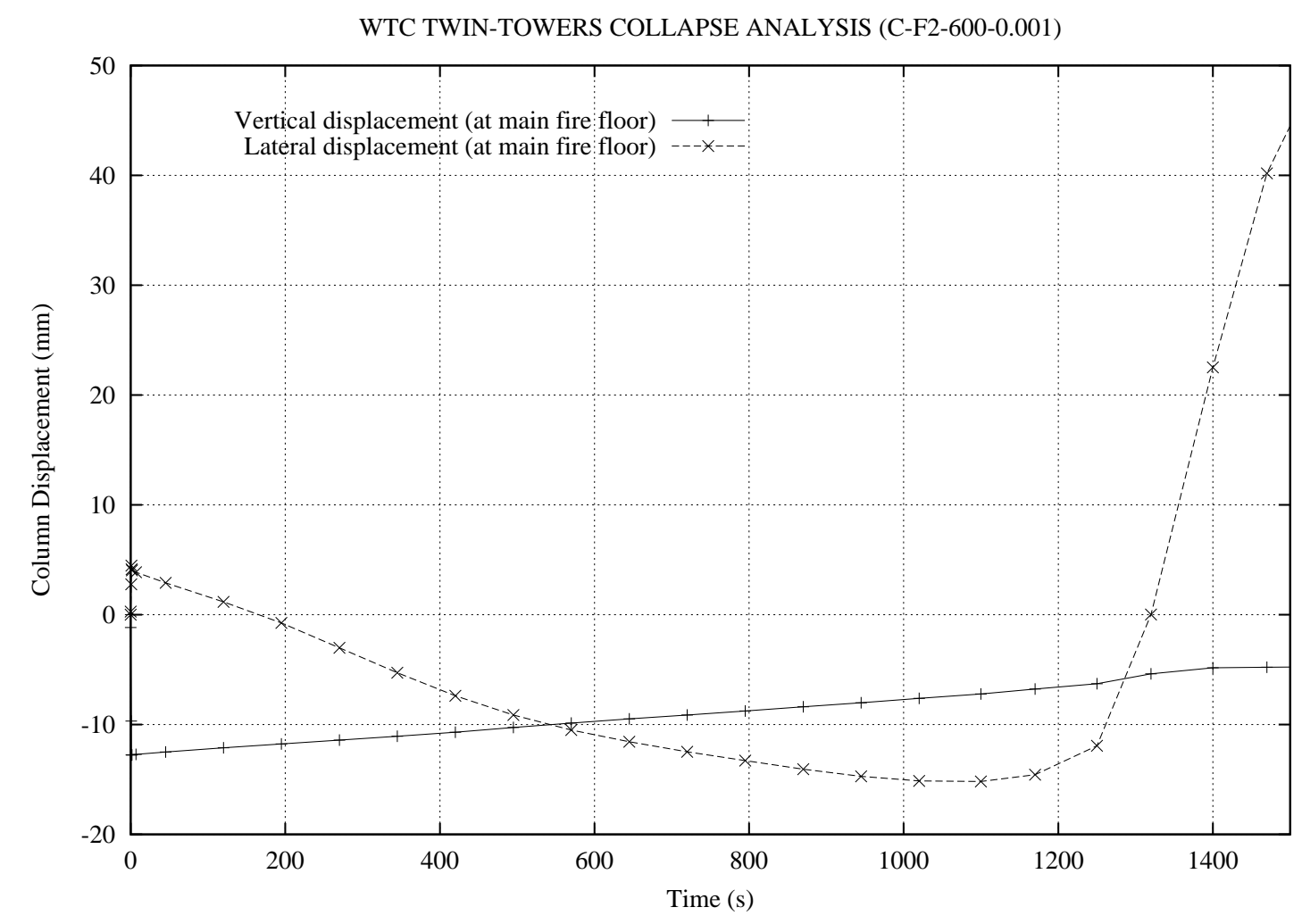

Figure 12: Column displacements at node 1072

WTC TWIN-TOWERS COLLAPSE ANALYSIS (C-F2-600-0.001)

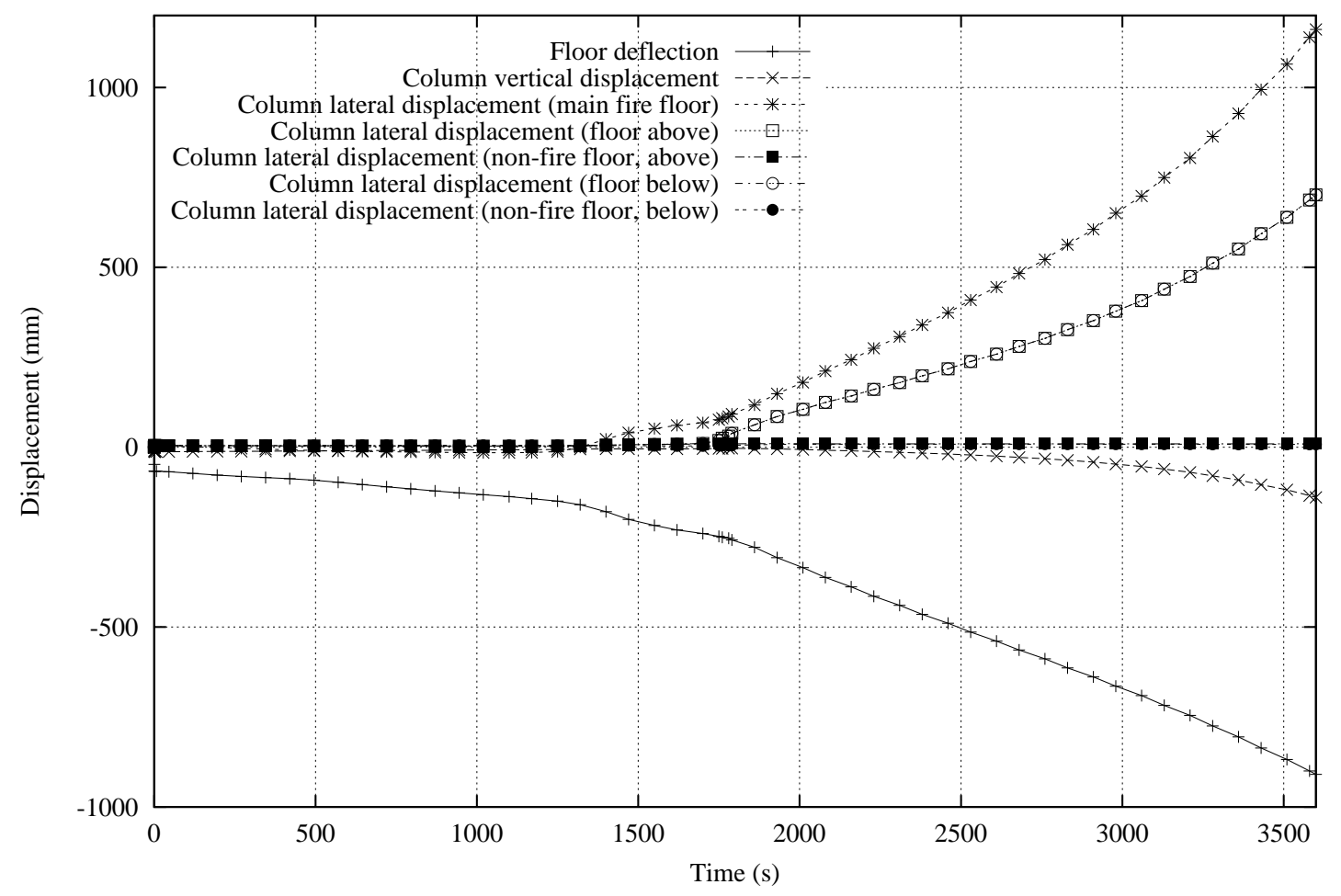

Figure 13: Column and floor displacement 
WTC TWIN-TOWERS COLLAPSE ANALYSIS (C-F2-600-0.001)

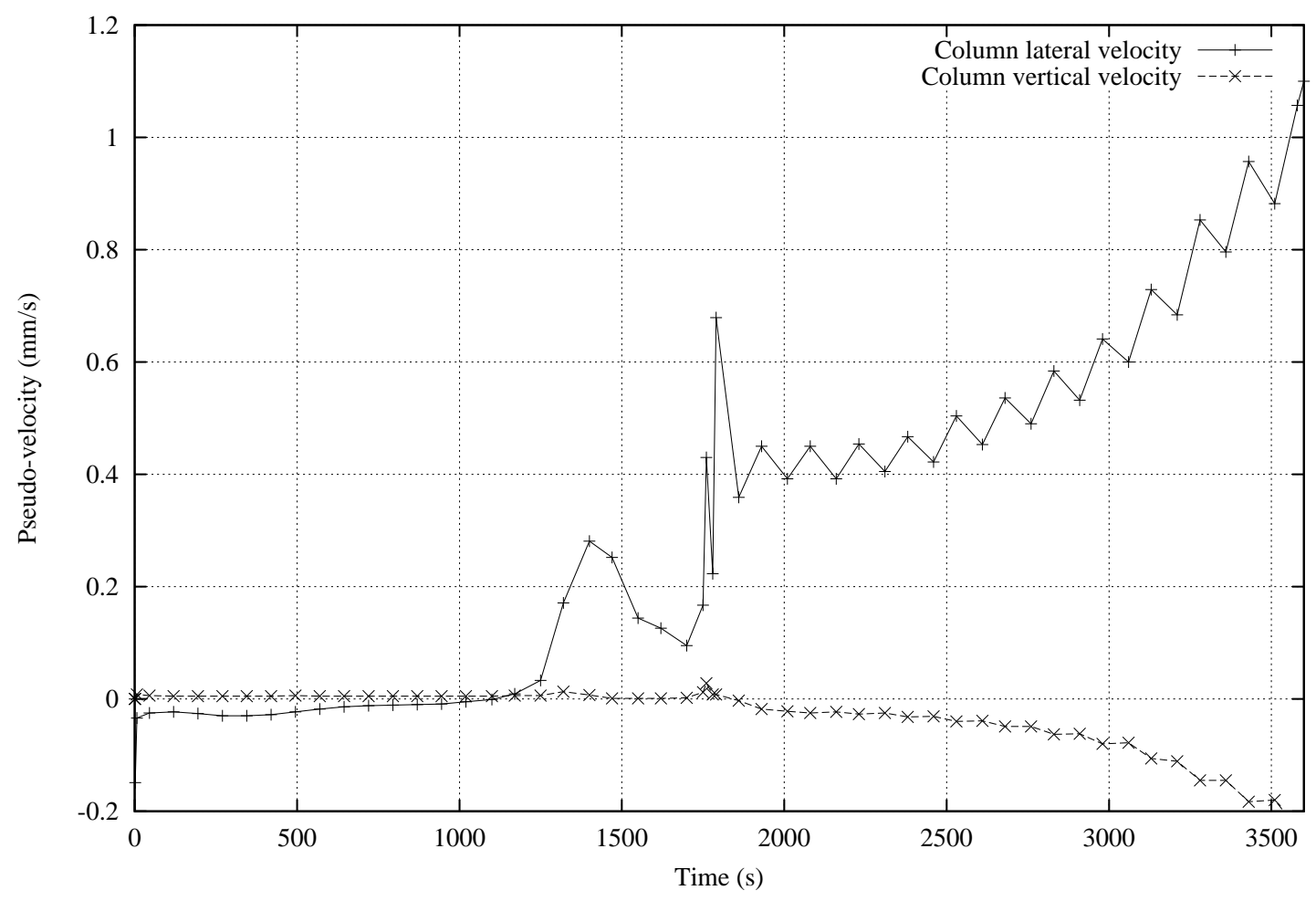

Figure 14: Column and floor pseudo-velocity

This Figure produces considerable new information that helps us understand the figures discussed earlier. The forces shown are simply the horizontal reaction provided by the supports on right hand side of the model (nodes 41036, 51036, 61036, 71036 and 81036 in Figure 10) as this reaction must equal the total axial force in the floors. Negative values of these reactions indicates compression and positive values indicate tension in the floor. We can see that initially the main fire floor experiences increasing compression (from restrained thermal expansion). However as these floor systems are primarily designed and optimised for out of plane loads (for an $18 \mathrm{~m}$ span!) they are very slender and can only resist very small amount of compressive force before buckling. This is what begins to occurs at approximately 1000 seconds and the lateral restraint provided by this floor rapidly disappears. It is interesting to note that the steel-truss temperature (same as compartment temperature) at this stage is under $400^{\circ} \mathrm{C}$ (see Figure 9) at which steel and concrete retain over $90 \%$ of its strength and stiffness. The mid-span deflection of the main floor at this time is approximately 130mm (see Figure 13). This deflection leads to considerable reduction in the geometric stiffness of the floor to axial forces to the extent that no further lateral restraint to the column can be provided at the main fire floor level. The floor then moves into tension at approximately 1300 seconds. Correlating this to the previous Figures 12 and 14 of displacement and velocity, it can be seen that the change in sign of the main fire floor axial force coincides with the change in sign of the column lateral displacement at this level and the acceleration of the column. The fire floor above, heated from below, also in compression and under large deflection suffers the same fate. The floor below, in contrast is heated from above, therefore only the concrete is heated and the average temperatures are very low and so are the deflections (see Figure 11). This leads to the axial force in this floor to be tension initially (as it reacts to the column moving outward), which changes to compression when the two floors above buckle inward. The top non-fire floor does the same. The resistance offered by these floors around 1500 seconds corresponds to the deceleration of the column in Figure 14. However the floor below the main fire floor eventually buckles as well at approximately 1700 seconds and moves into tension. The tensile forces in all three 
fire floors reduce practically to zero by the end of the analysis.

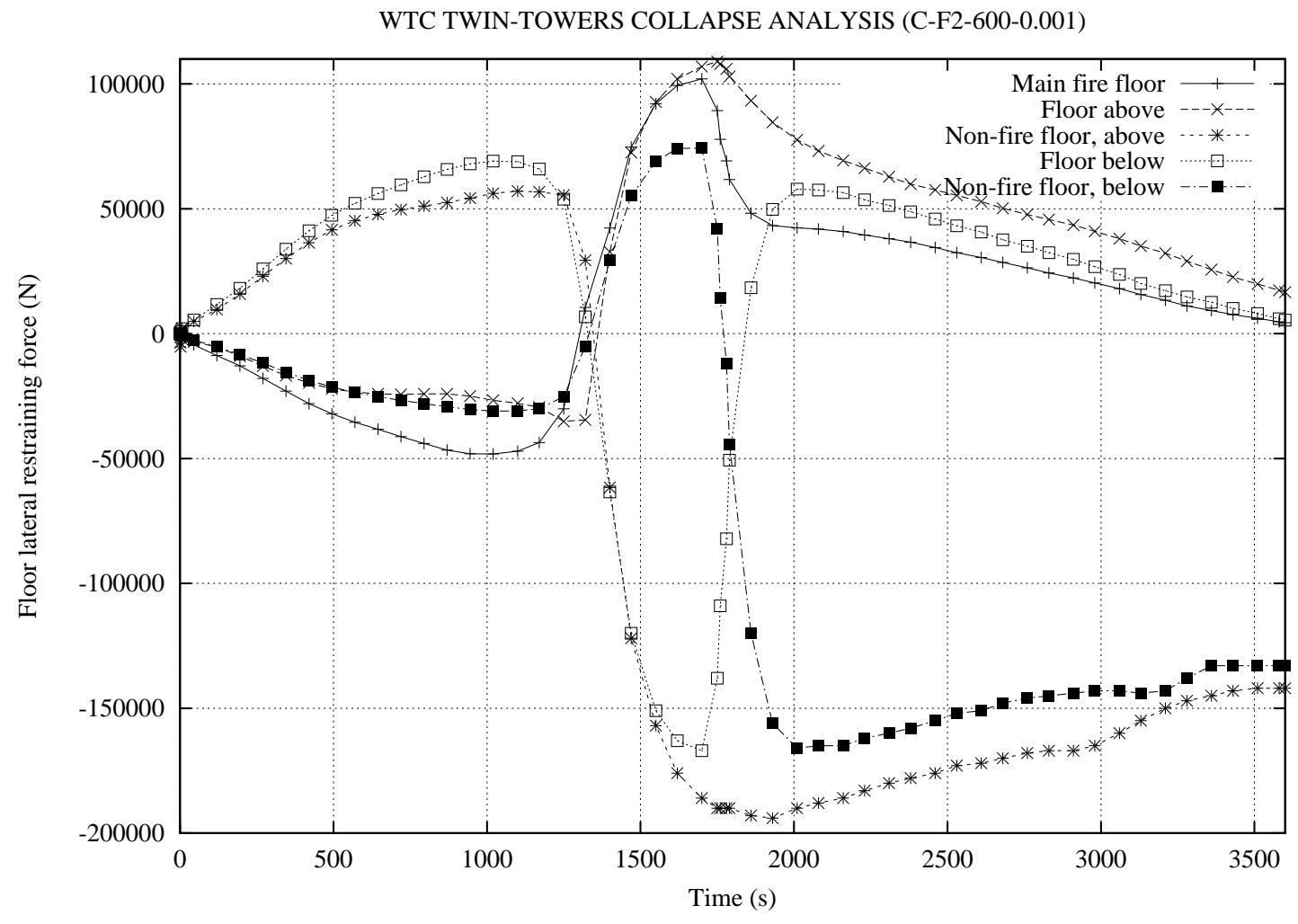

Figure 15: Floor lateral reaction to column

Figure 16 shows the axial load-displacement paths of the three fire floors through a range of column displacement from $-15 \mathrm{~mm}$ to $50 \mathrm{~mm}$. The main fire floor shows a reasonably steady compressive membrane stiffness until it buckles. Beyond this point the path is not particularly meaningful there are tensile membrane forces in the floor which may contribute to the inward movement but are not entirely responsible for it. The relatively cool floor below the main fire floor initially has tensile forces (as seen in Figure 15), however as soon as the lateral restraint stiffness of the two floors above is lost, this floor resists the column collapse and buckles at a much higher load (as the midspan deflection of this floor is low therefore the axial restraint stiffness is much higher).

Figure 17 shows an explicit calculation of the stiffness of the main fire floor and the floor above, by dividing the axial force increment in a time interval with the lateral displacement increment. This Figure shows that the axial restraint stiffness of the main fire floor disappears after 1000 seconds.It reappears later, but this is really tensile stiffness to support the floor loads in tensile membrane action, which also contributes to destabilising the column. The floor above initially reduces in stiffness as most of the lateral support is being provided by the main fire floor (due to the largest column displacements at that level). When the main fire floor stiffness disappears, there is a large peak in the stiffness of the floor above as it takes-over the column lateral support from the main fire floor. This leads to buckling of the floor above as well and its lateral restraint stiffness disappears as well and then reappears in the tensile membrane form.

The discussion above provides a complete description of how the structure collapses. This is exactly consistent with the original hypothesis. Figure 18 shows the model collapsing exactly in the manner predicted by the figures in the hypothesis.

Model with double column, 2 -floor fire scenario $\mathbf{C}, a=0.005, T_{\max }=700^{\circ} \mathrm{C}$ 
WTC TWIN-TOWERS COLLAPSE ANALYSIS (C-F2-600-0.001)

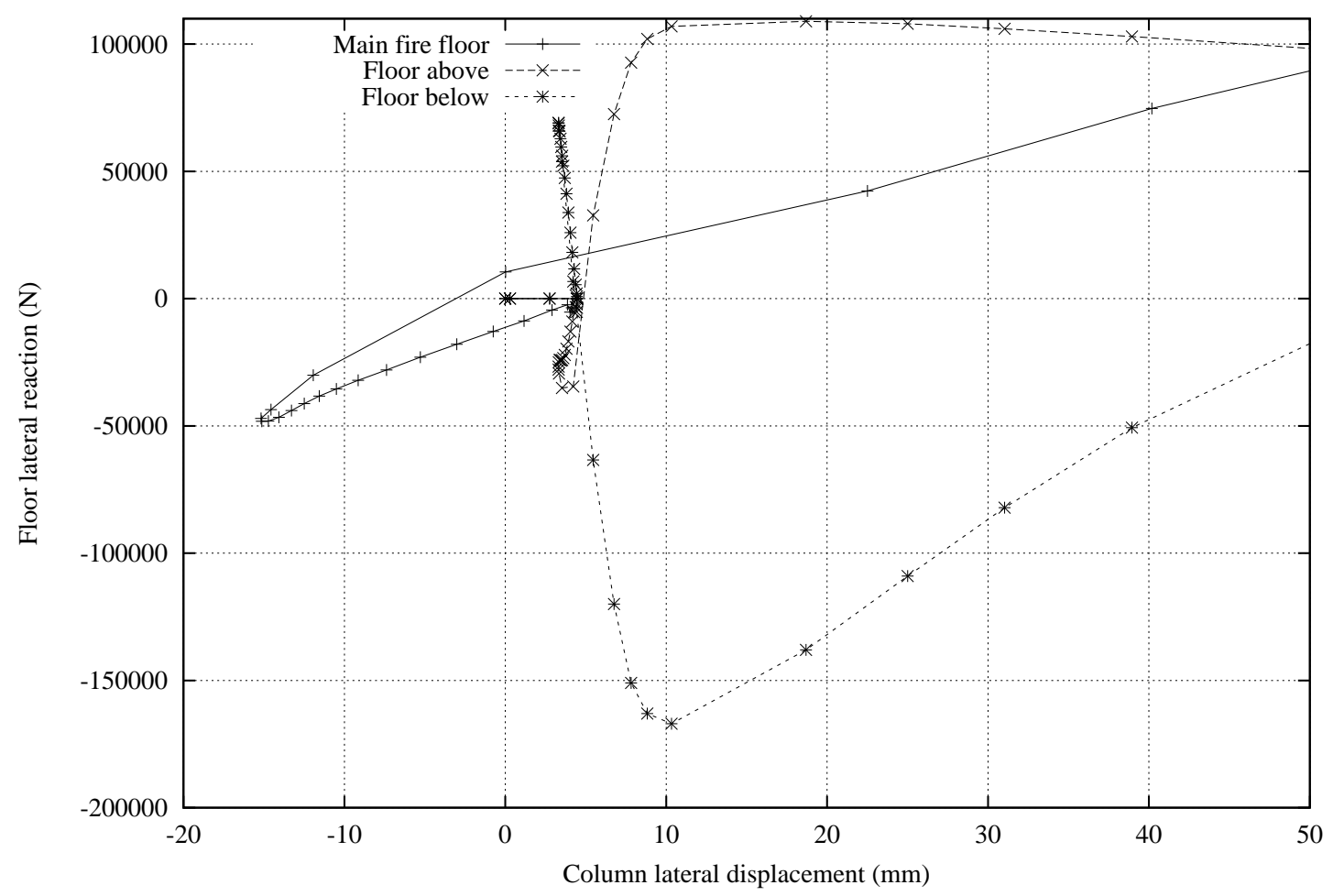

Figure 16: Floor lateral reaction against column lateral displacement

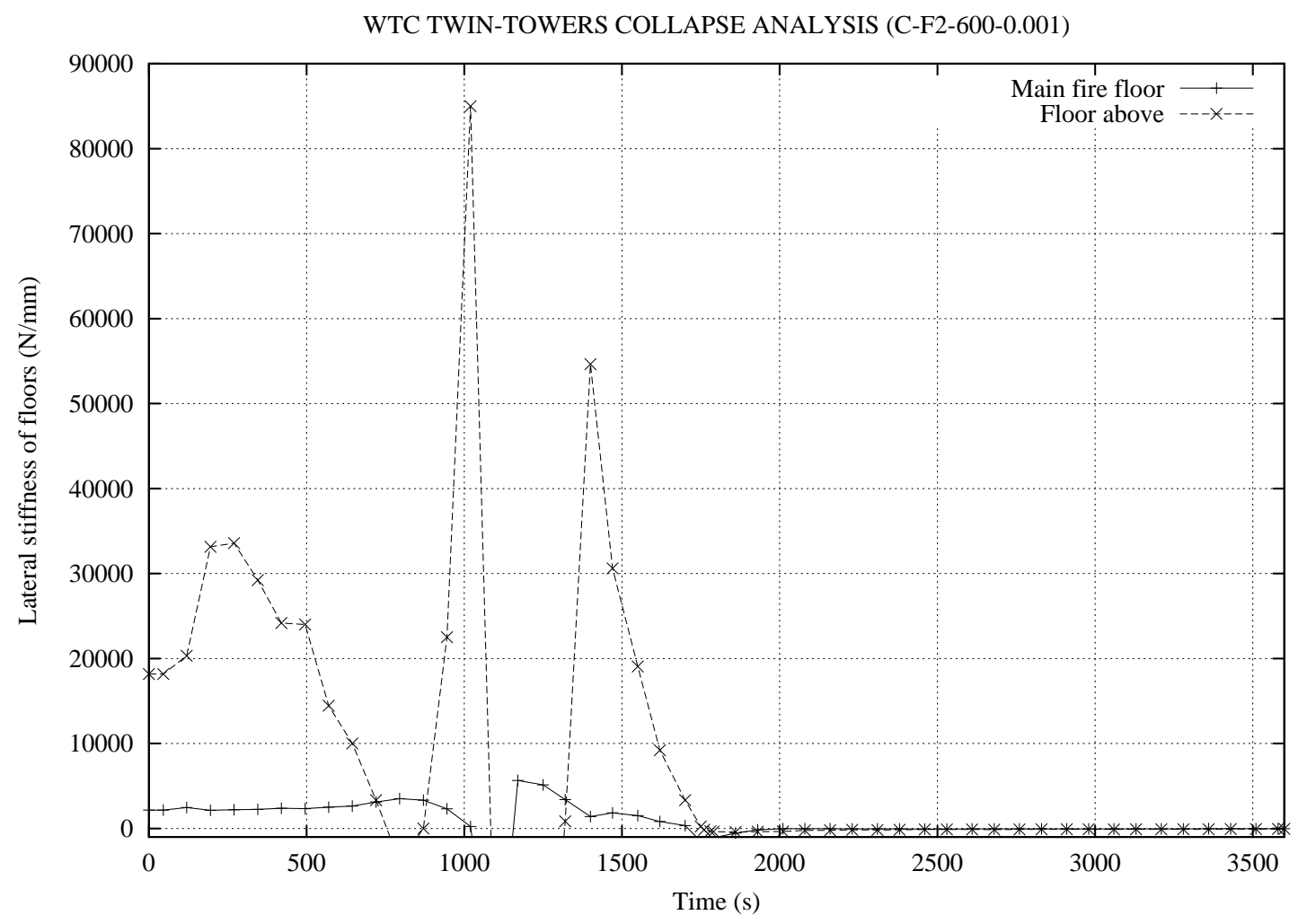

Figure 17: Floor lateral stiffness 


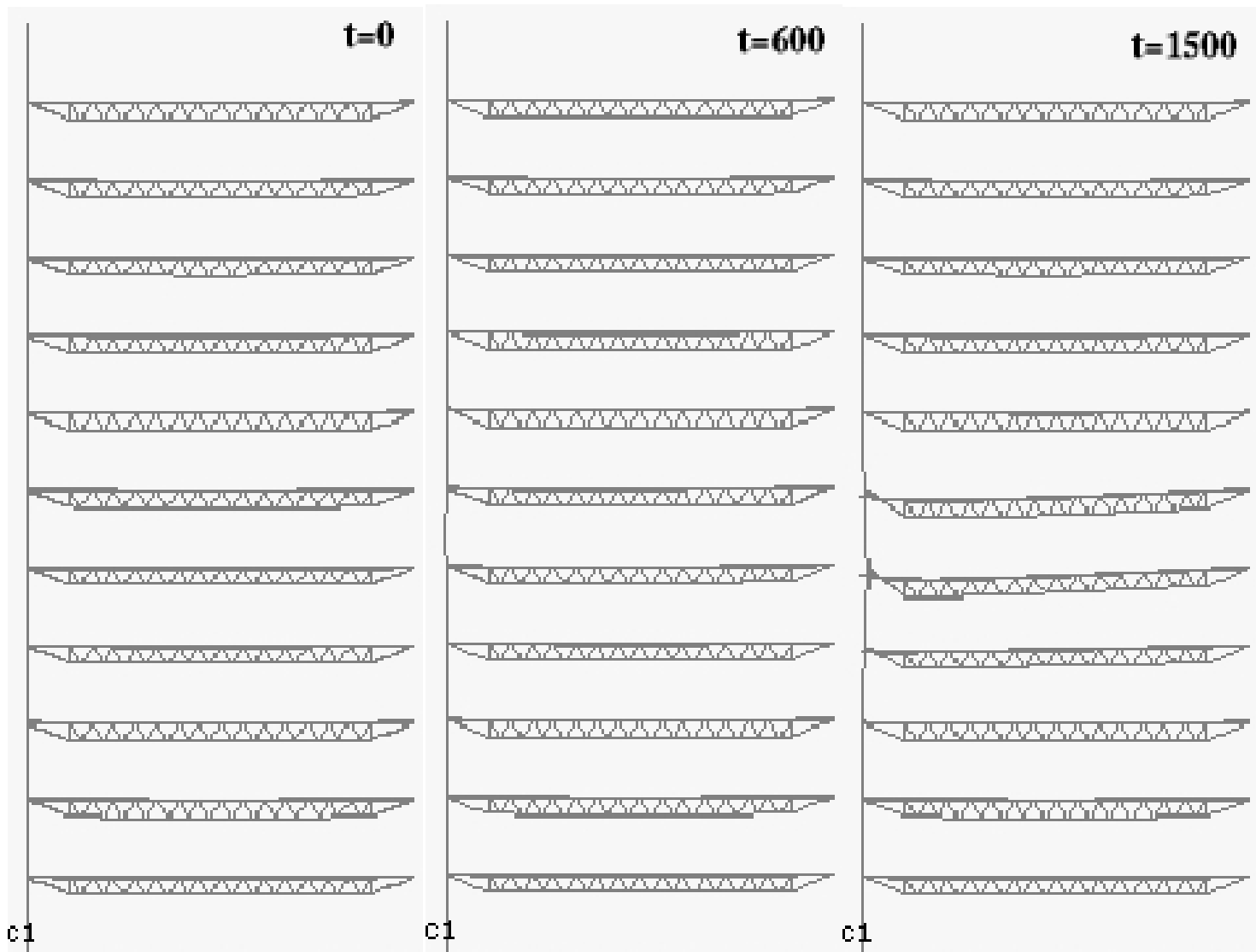

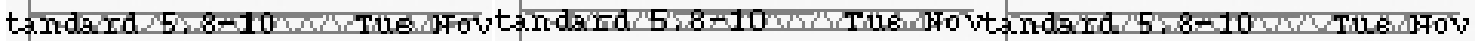
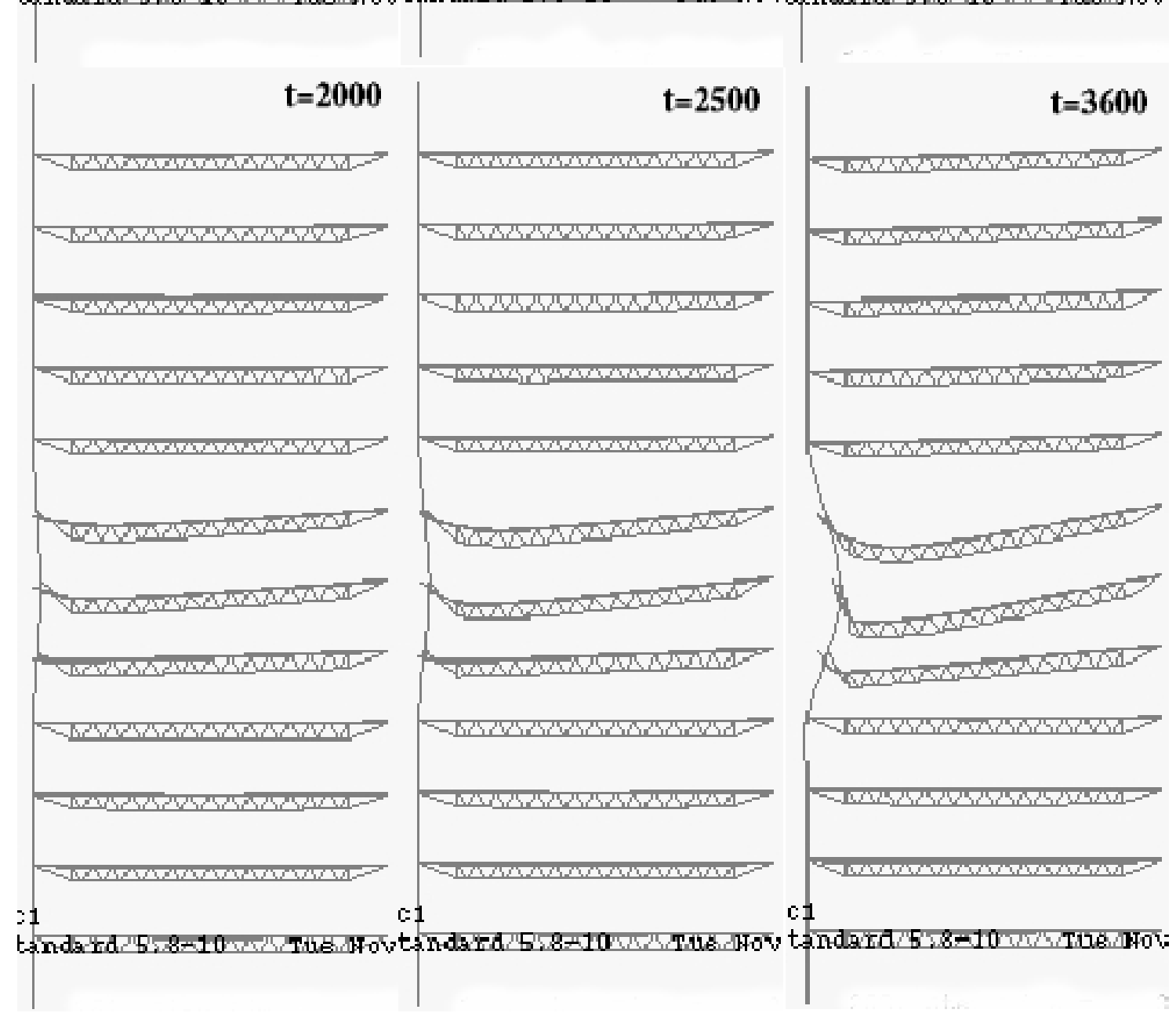

Figure 18: Model showing collapse, fire scenario $\mathrm{C}, T_{\max }=600^{\circ} \mathrm{C}$ and $a=0.001$ for fire on 2 floors 
The case discussed previously assumed that a single outer column was supporting the load of a $2 \mathrm{~m}$ wide floor strip. We now consider the model where this load is assumed to be supported by two columns. As mentioned earlier, this is a better representation of the structure and the analyses are therefore of greater relevance. The fundamental collapse mechanism does not however change. The failure envelope for the two column model is presented in Figure 19. It may be noticed now that no collapse occurs for any of the 1-floor fire scenarios. However collapse still occurs for 2-floor fire scenarios but at relatively higher temperatures $\left(700^{\circ} \mathrm{C}\right.$ and over). However for the 3 -floor fires, collapse still occurs at temperatures as low as $500^{\circ} \mathrm{C}$, even with scenario $\mathrm{C}$.

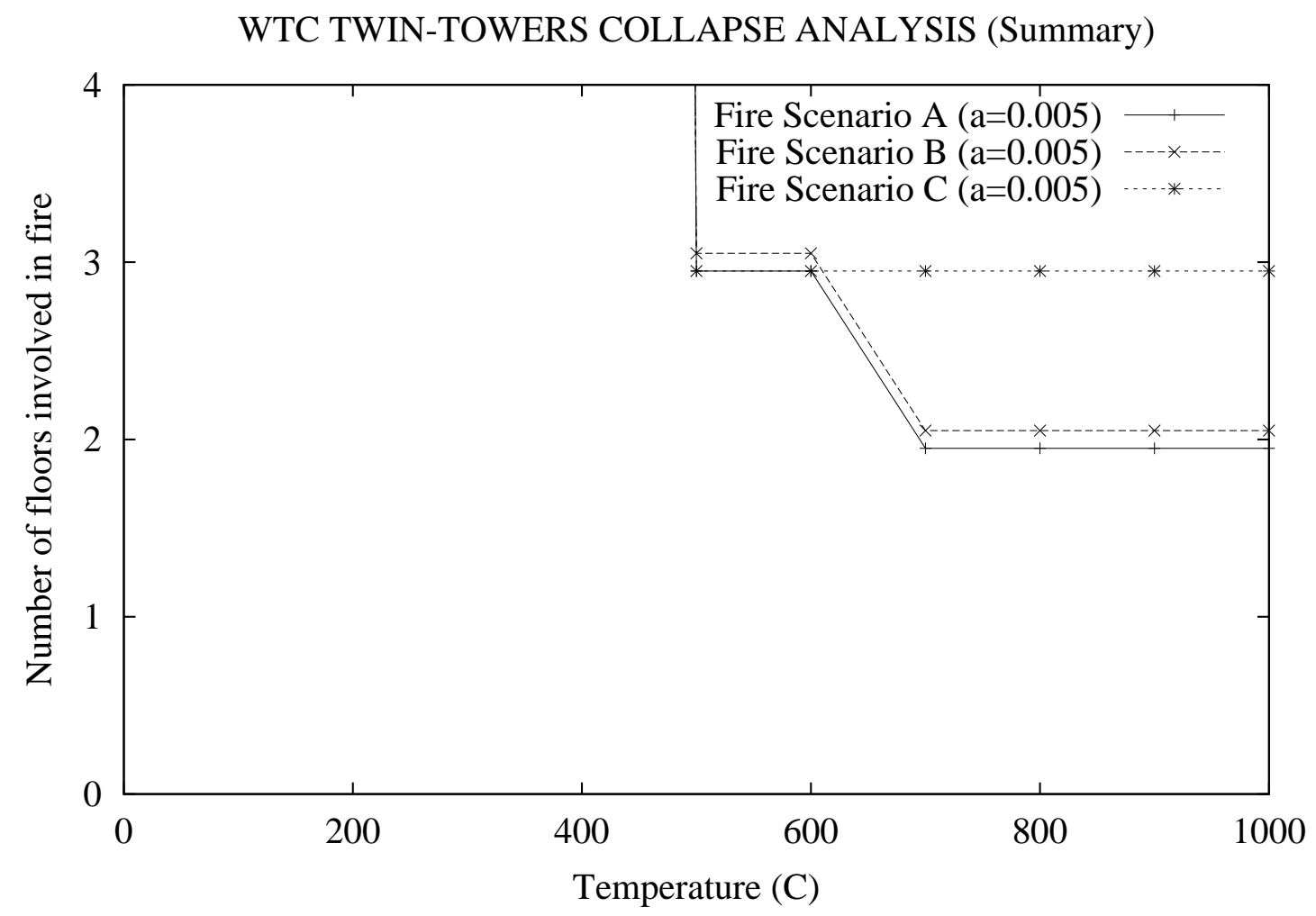

Figure 19: Failure envelope from all scenarios analysed for the double column model

The results of this model are presented here as it shows a contrast to the unstable behaviour seen in the previous analysis. Figure reference 20 shows the deflections of the fire floors and column lateral and vertical displacements at its connection with the hottest fire floor (main floor). Although the floor deflections continue to increase, the column lateral displacement stabilises, after the expansion and reversal as notices in the analysis discussed previously. Furthermore, the column continues to displace upward (positive) right to the end of the analysis, suggesting the structure is stable. The same general conclusion is offered when the floor lateral reaction forces are examined (see Figure 21). The column lateral pseudo-velocity (Figure 22) is seen to become nearly zero after about 1500 seconds, again suggesting that the structure remains stable. Finally, Figure 23 shows the floor lateral reaction plots against column lateral displacement. This plot shows again that the floors expand laterally with a constant stiffness at first and then buckle and begin to act in tension as seen before.

Model with double column, 3-floor fire scenario $\mathbf{C}, a=0.005, T_{\max }=500^{\circ} \mathrm{C}$

This final discussion focuses on a 3 -floor fire case with a moderate temperature, which clearly shows the onset of collapse. Figures reference 24 and 25 show the deflections of the fire floors and associated column lateral displacements. All displacements are seen to be accelerating to the end of the analysis, suggesting impending instability. Figure 26 clearly shows this as columns beginning to displace 
WTC TWIN-TOWERS COLLAPSE ANALYSIS (C-F2-700-0.005)

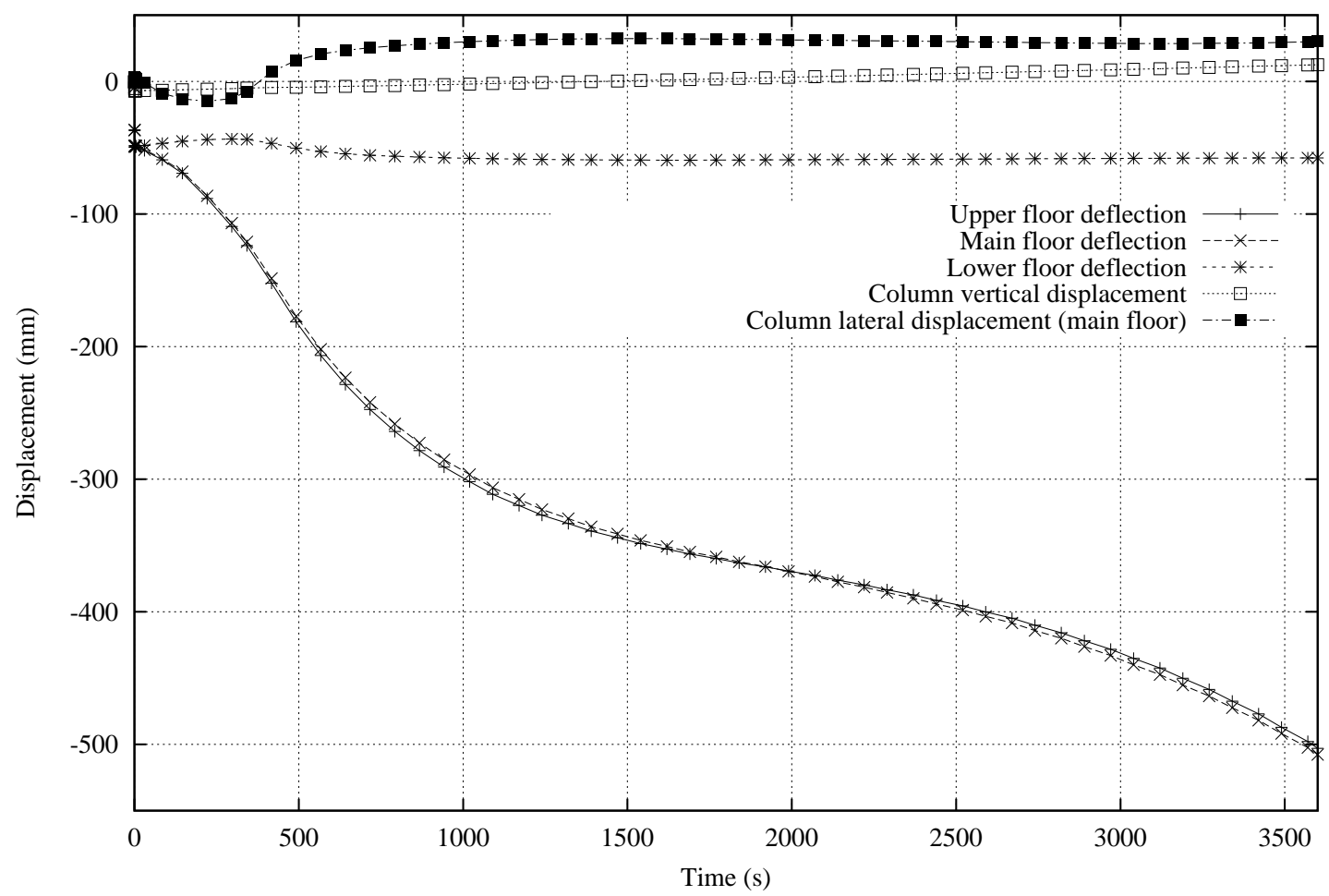

Figure 20: Floor and Column displacements

WTC TWIN-TOWERS COLLAPSE ANALYSIS (C-F2-700-0.005)

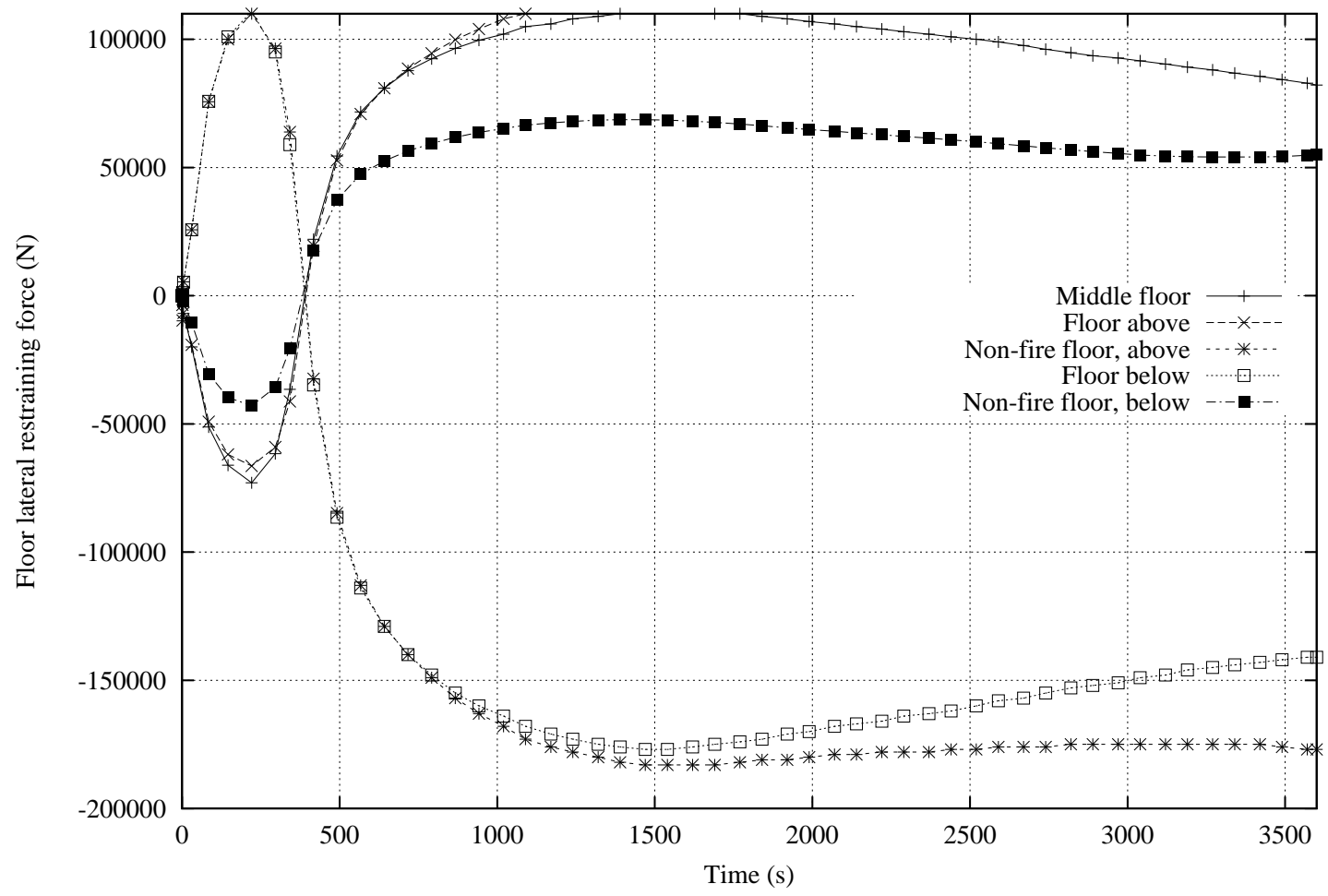

Figure 21: Floor lateral reaction to column 


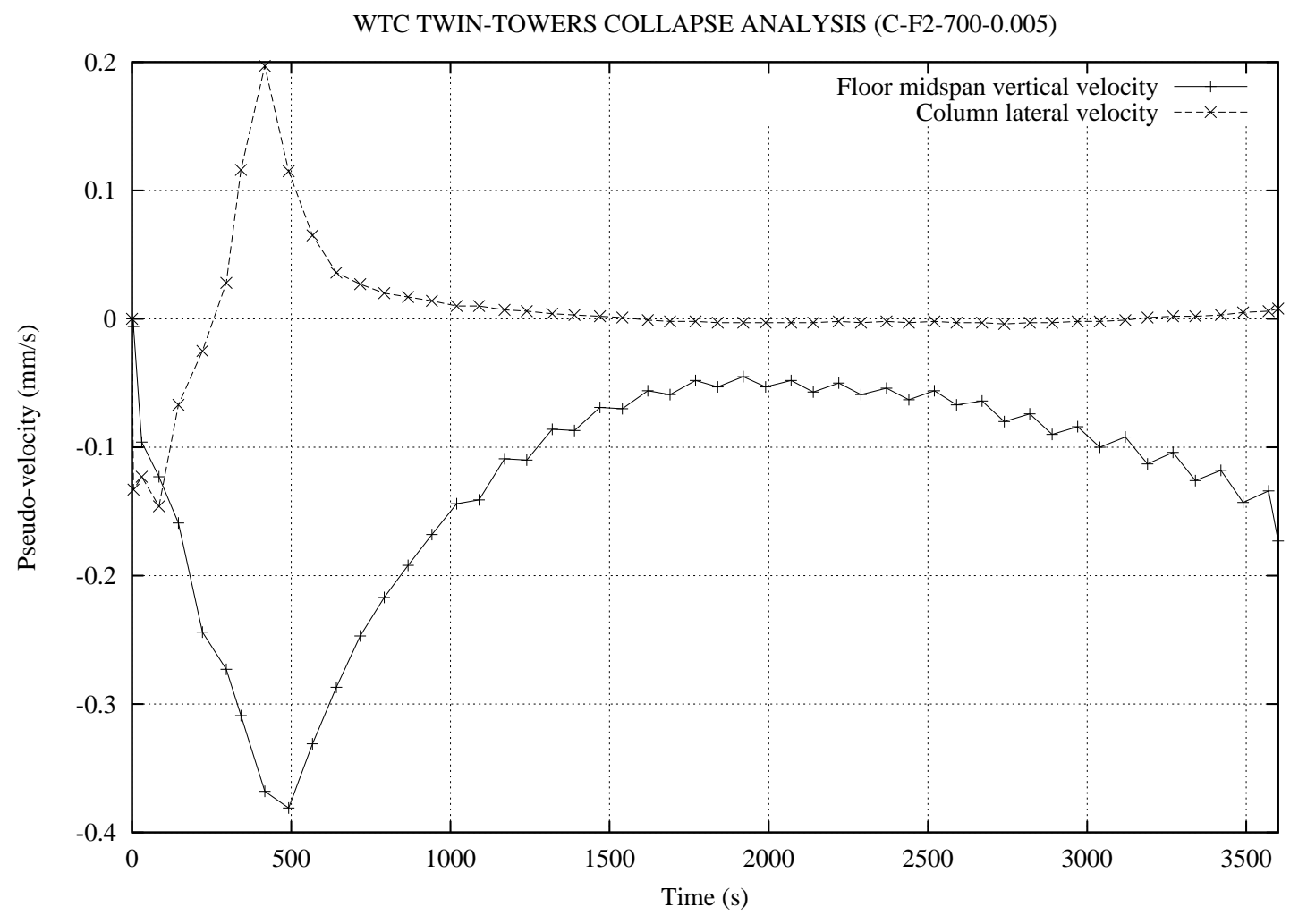

Figure 22: Pseudo-velocity

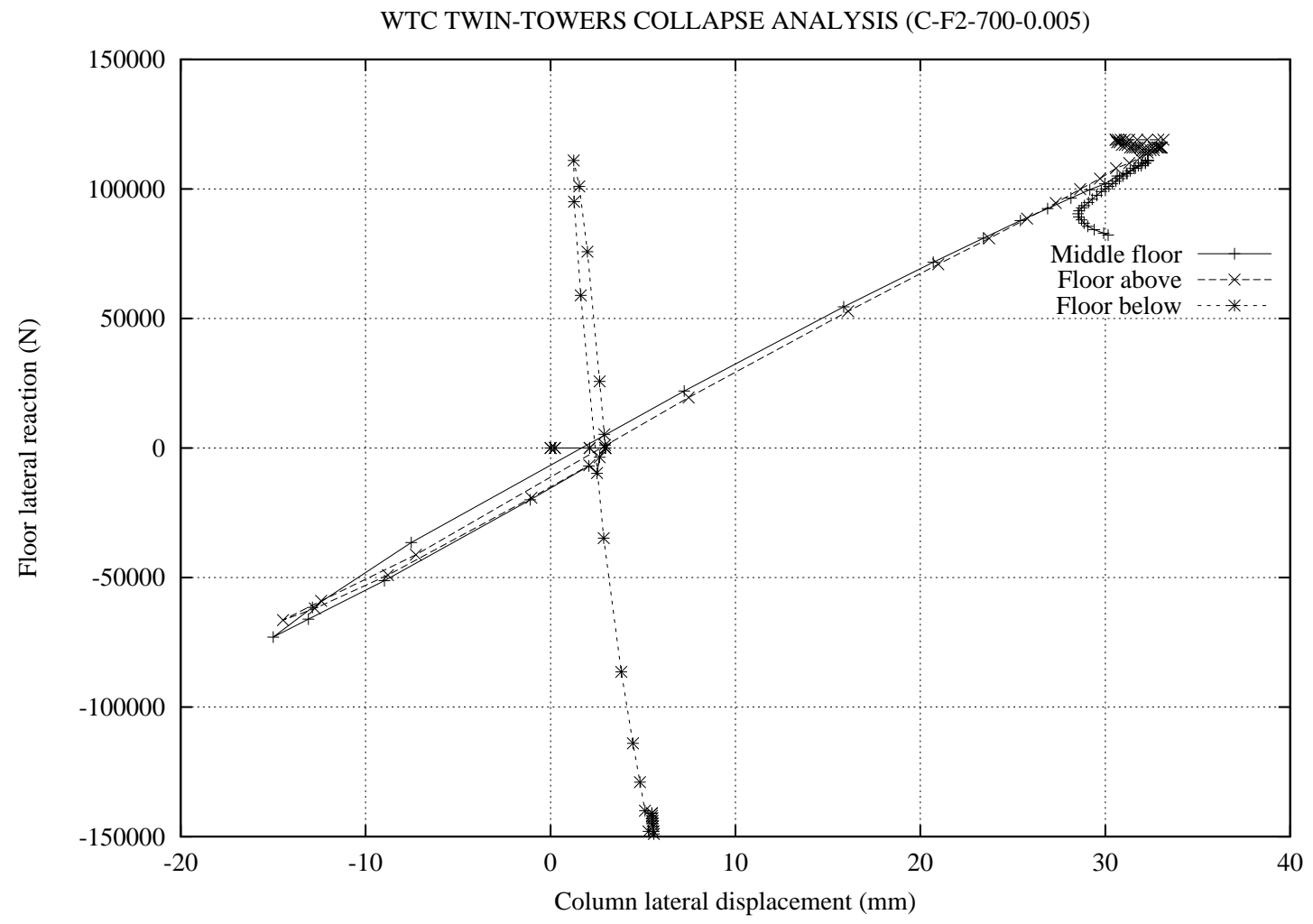

Figure 23: Floor lateral reaction against column lateral displacement 
downwards after about 3000 seconds. The floor lateral reaction forces (see Figure 27) have also come close to zero at this time. The variations in floor reactions have a direct link to the pseudo velocity plots (Figures 29 and 28). This can be seen by matching all the large reversals in velocities with various floors moving from compression to tension in Figure 27. This provides an insight into the progressive nature of the eventual collapse. Figure 29 shows that after about 2800 seconds both columns begin to accelerate downwards. Figure 30 provides an insight into floor stiffness variation and the interactions taking place between floors and columns.

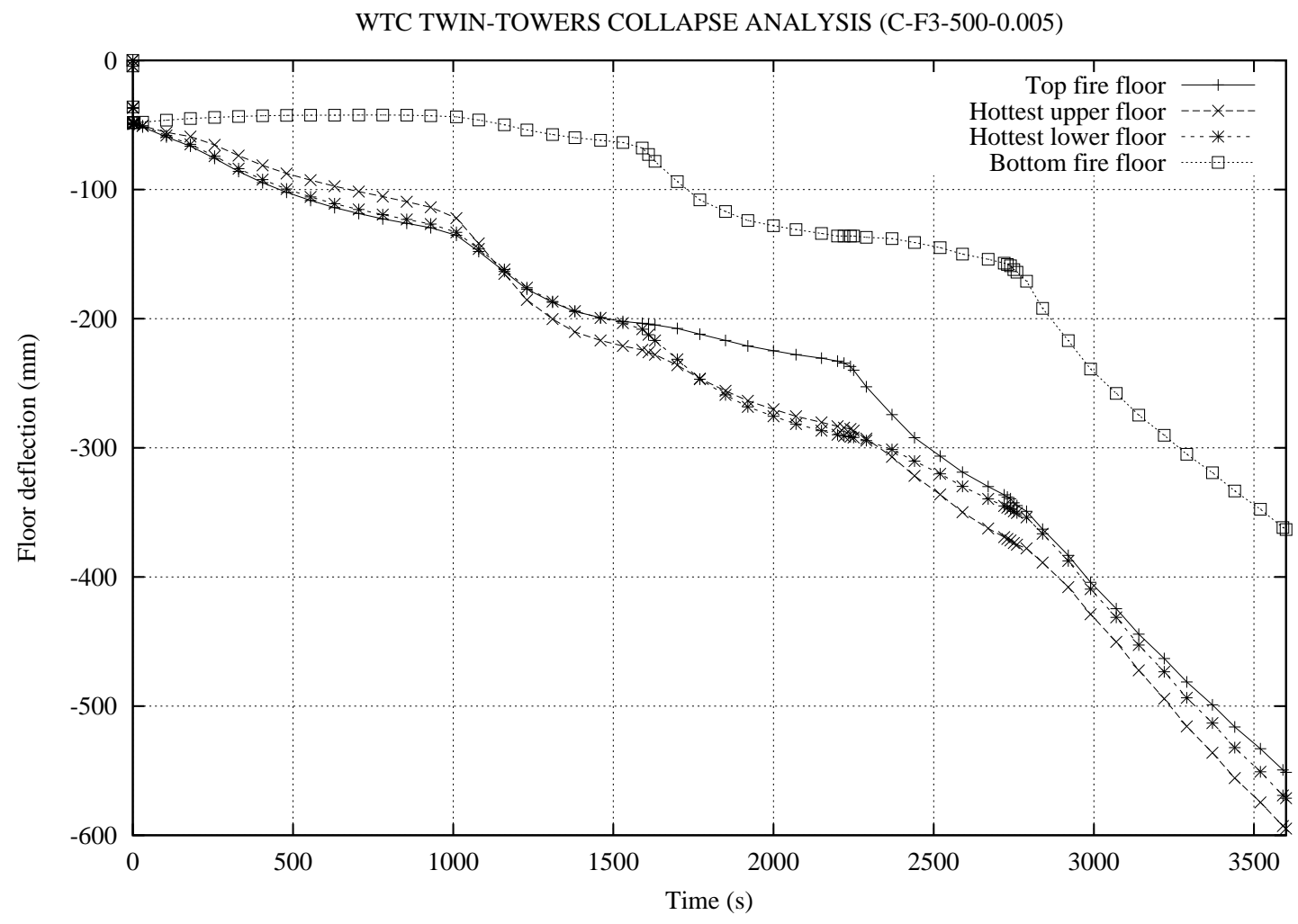

Figure 24: Floor deflections

\section{DISCUSSION}

If the models above are considered a reasonable structural equivalent of the WTC Towers, it is clear that the overall structural stability failure of the columns would occur even at low temperatures. This is primarily because of the degradation of lateral support from the composite truss floor system which was too slender to continue to supply the column lateral support demand. The maximum temperature of the columns themselves has been limited to $400^{\circ} \mathrm{C}$ (often not reached as failure occurred before this temperature is attained). At such temperatures the columns are expected to retain over $90 \%$ of their axial stiffness, which would be sufficient to continue supporting the loads (given the low utilisation factors of column axial capacity when gravity load resistance is the only demand). However the loss of lateral support from one or more of the composite truss floors will clearly reduce the gravity load capacity (Euler buckling load is reduced to $25 \%$ for the loss of just one floor). This potentially points to the most likely failure initiation mechanism (note there is no requirement of connection failures for this mode of failure to occur - clearly the connections will fail once the collapse is initiated, but this is 'effect' not 'cause'). To elaborate further, the main mechanisms by which the loss of lateral support occurs are discussed below:

1. The most obvious means by which the lateral support to the columns may degrade would be the 


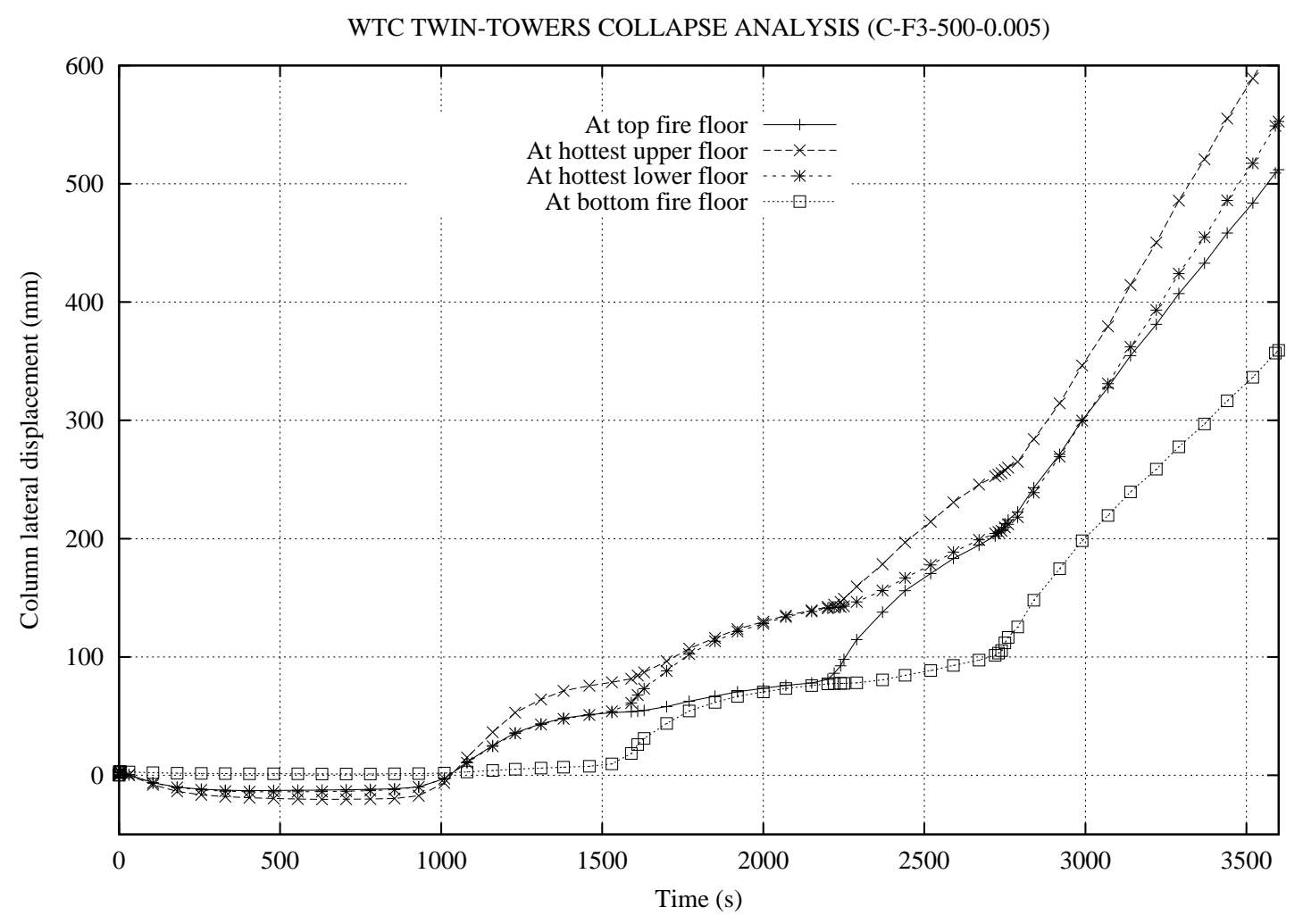

Figure 25: Column lateral displacements

WTC TWIN-TOWERS COLLAPSE ANALYSIS (C-F3-500-0.005)

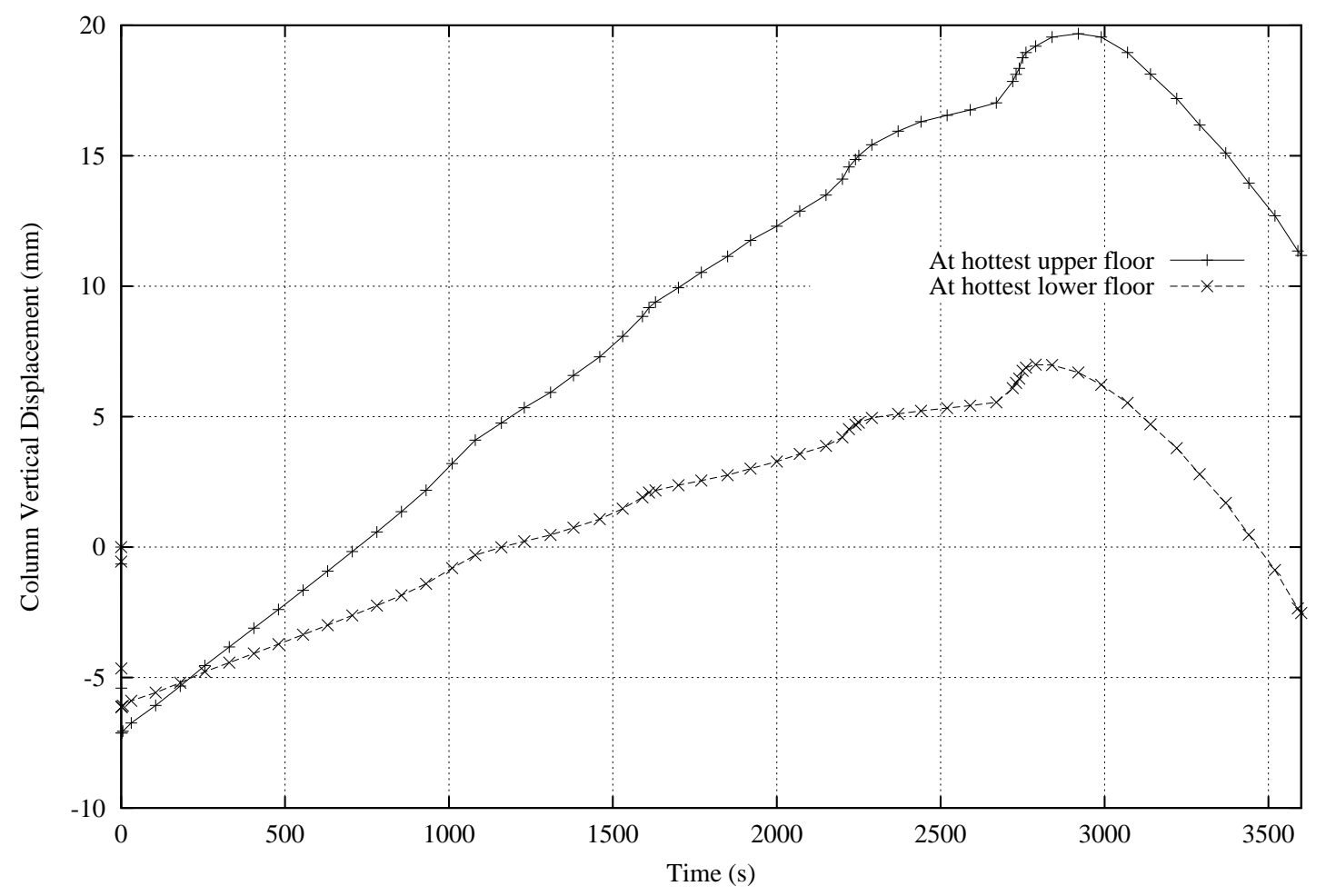

Figure 26: Column vertical displacements 


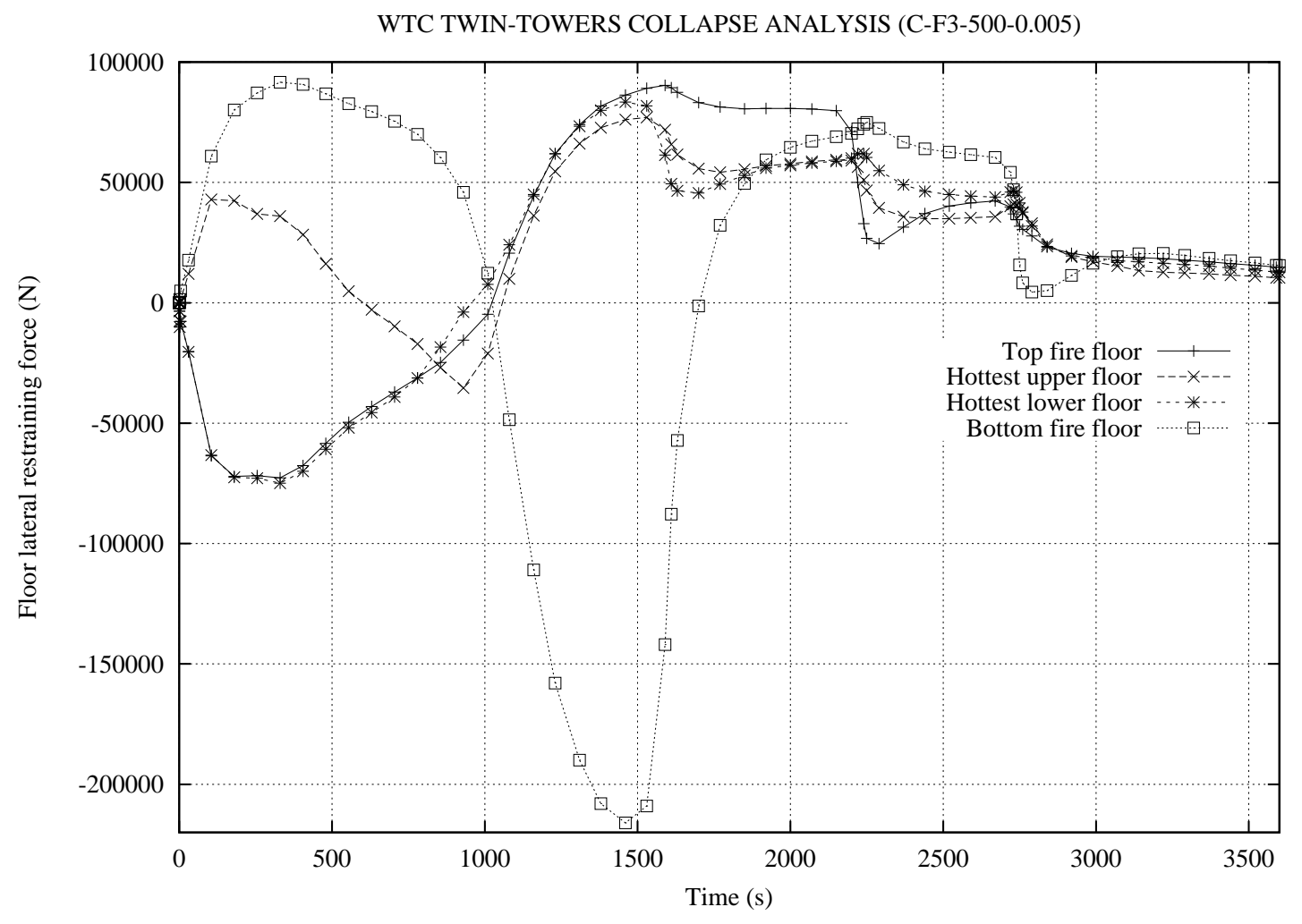

Figure 27: Floor lateral reaction to column

WTC TWIN-TOWERS COLLAPSE ANALYSIS (C-F3-500-0.005)

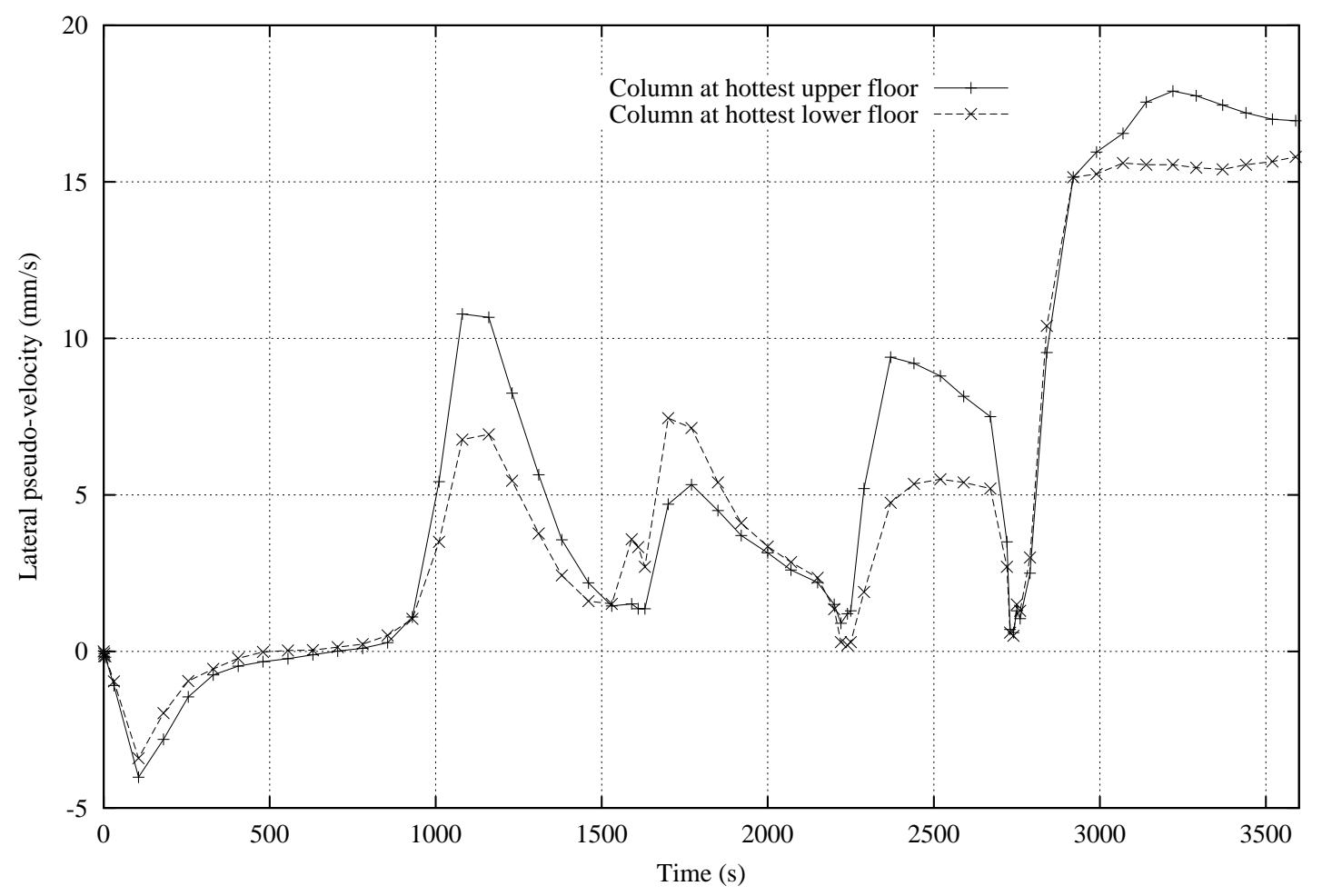

Figure 28: Lateral pseudo-velocity of columns at hottest floors 
WTC TWIN-TOWERS COLLAPSE ANALYSIS (C-F3-500-0.005)

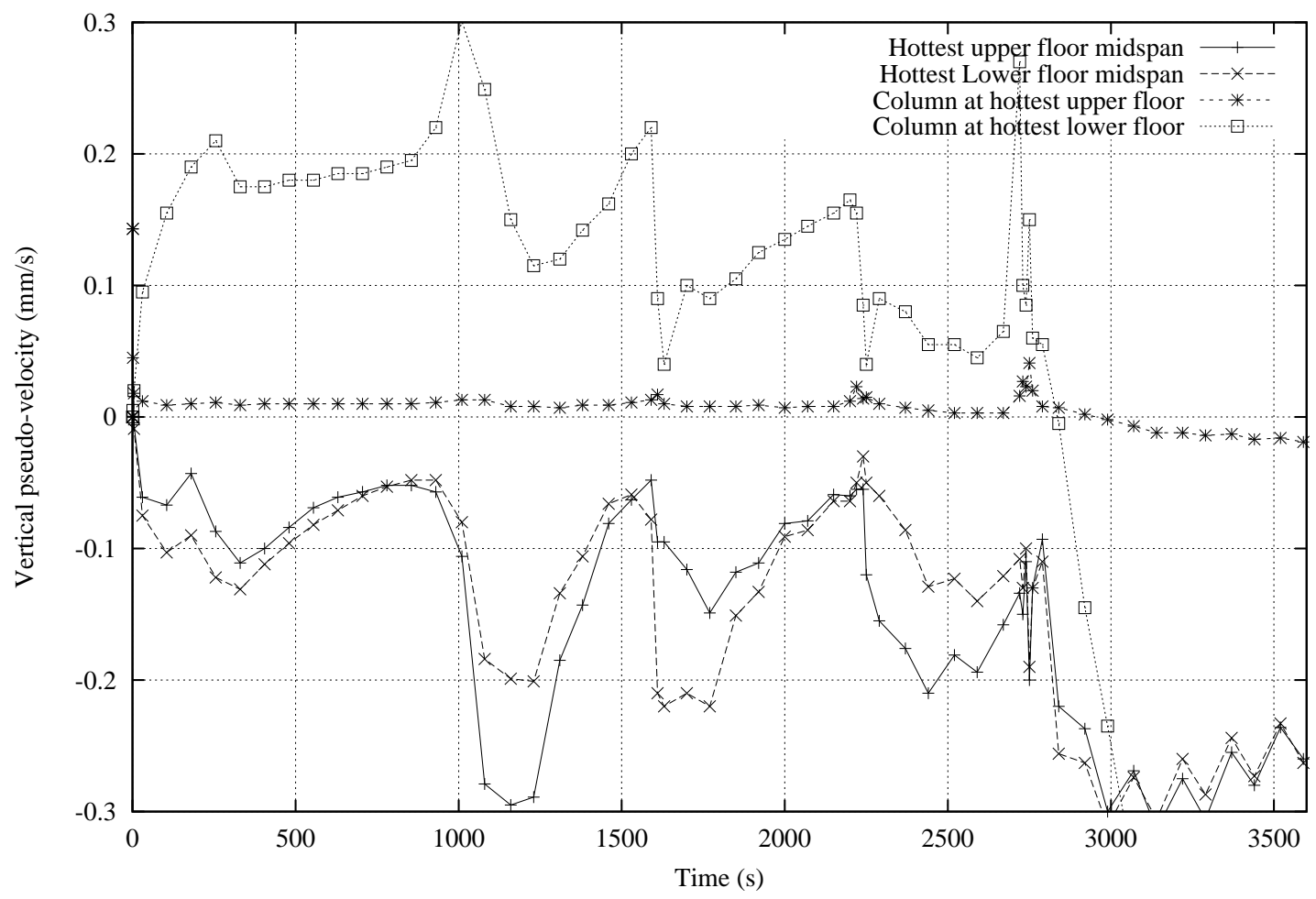

Figure 29: Vertical pseudo-velocity of columns and hottest floor midspans

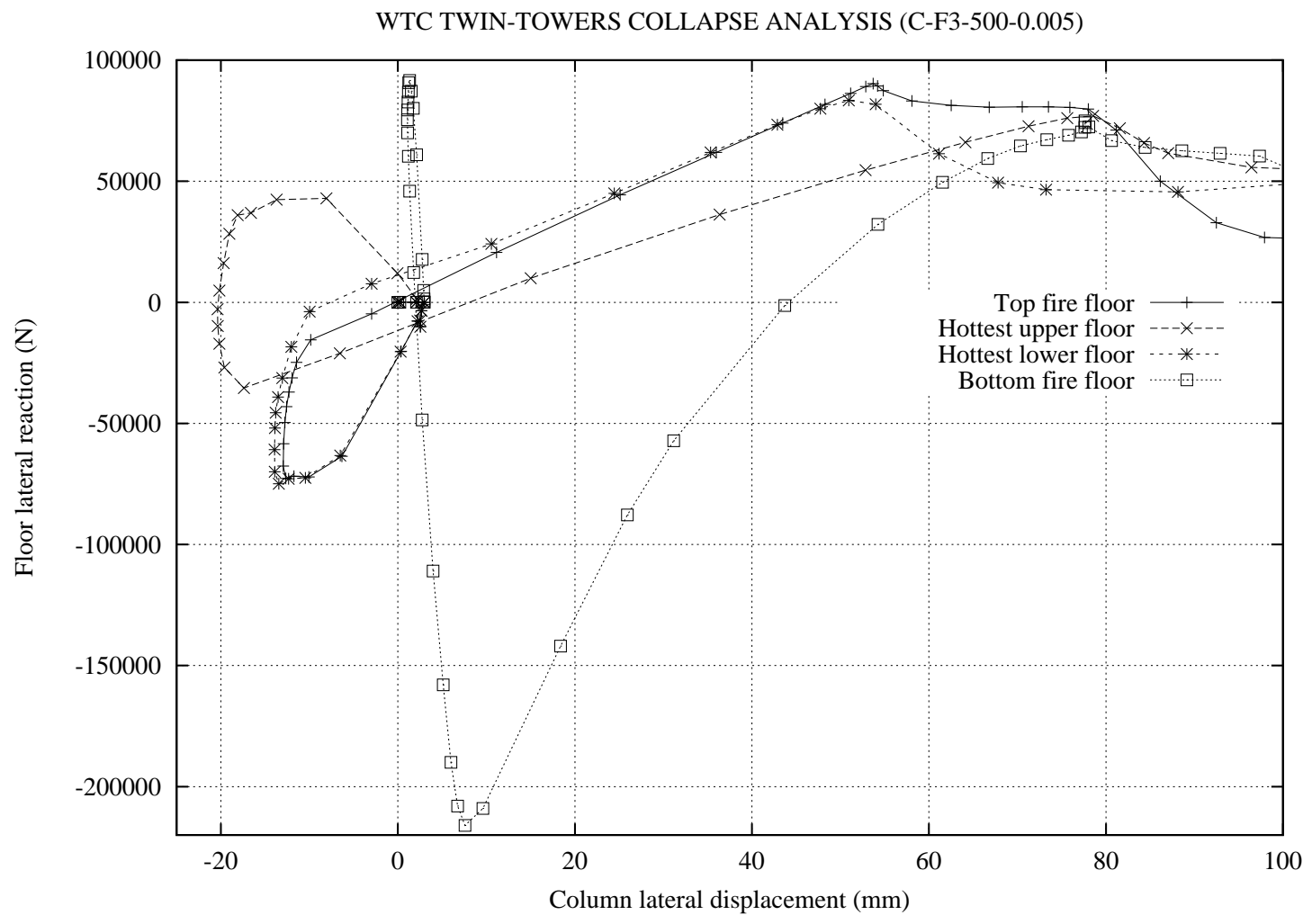

Figure 30: Floor lateral reaction against column lateral displacement 
softening of the steel truss members from heating resulting in the loss of stiffness and strength. This softening would be particularly severe if it is assumed that the truss members had lost a significant proportion of their fire protection at impact (as all the truss components were rather light and would heat up very quickly without protection). This case is covered by the analyses which assume rapid rise of compartment temperature (values of $a=0.005$ ). Even with the stronger two-column models (see Figure 19) collapse occurs at truss temperatures of $500^{\circ} \mathrm{C}$ for all three-floor fire scenarios and at $700^{\circ} \mathrm{C}$ for two-floor scenarios $\mathrm{A}$ and $\mathrm{B}$

2. The second and even more significant effect of fire on structural members is that of restrained thermal expansion (thermal bowing is of lower importance for multiple floor fires). The significance of this effect is often under-estimated by most fire professionals. In conventional steel frame composite structures (such as Cardington), this effect is generally beneficial. It reduces the internal forces that a structural member experiences when heated (while restrained at the ends) as out-of-plane displacements limit the mechanical stresses and consequent damage. It also helps to create a favourable deformed shape of the composite floor system that allows the structure to effectively deploy secondary load carrying mechanisms of membrane tension (and compression) when the bending capacity is reduced or exhausted by the effects of heating. This same behaviour however can have a seriously detrimental effect on the lateral support providing capacity of the floor system. If the floor system is very slender (as was the case for the WTC Towers), only a small amount of heating will make it buckle out of plane (because of restrained thermal expansion). This is clearly seen in the analysis presented above. This leads to a degraded axial stiffness (and thus the capacity to provide lateral support) due to the deformed geometry. For slender floor systems this occurs much earlier than the material softening effect. It is also quite possible, if this effect is large enough, that the lateral support capacity could be lost well before the material properties are significantly reduced. For many of the cases studied above, collapse is initiated before the steel truss reaches $500^{\circ} \mathrm{C}$. This suggests that even if the fire protection to the steel trusses had survived the impact, the failure temperatures required could have been attained

3. The third and further destabilising mechanism is that of the effect of thermal expansion of the floor system against the columns. The internal boundaries (core) would have been considerably stiffer because of the continuity of the structure beyond the composite truss floor system and because of the considerably lower temperature in the core region (as discussed earlier). The external boundaries by contrast were much softer (columns in flexure/shear against the floor in membrane compression). Therefore to begin with, the columns would displace laterally outward. Meanwhile as the columns are also heated the overall compression forces in the columns are also increased. The combination of the added eccentricity from the outward displacement and the increased compressions add to the destabilisation effect on the column. However this is essentially a stable and self limiting configuration, because the additional eccentricity is essentially a compatibility phenomenon and the columns displace to accommodate the expanding floor (which is always in compression in this situation therefore the connections are not at risk). In none of the analyses carried out failure occurred by outward buckling of the columns

4. It is clear that the thermally expanding truss floor system initially pushes the column out (while it is sufficiently stiff in membrane behaviour). As the membrane stiffness reduces (through either geometric or material effects), the outward movement of the column is arrested and the stored strain energy in the column makes it recoil with an increasing rate of inward displacement pushing the softened floor system back in. This is seen in the pseudo-velocity plots earlier. A point to note here is that there is potentially a dynamic magnification effect here (not considered in this analysis) which could be another possible factor contributing to the instability. 
The column eventually over-shoots the original position significantly and the eccentricity thus caused is quite different from the relatively stable configuration when the floors were pushing the columns out. The floor meanwhile has been pushed beyond its original position and deflections therefore increase to the extent that the membrane compression now changes to membrane tension, adding further to the destabilising force on the column, potentially triggering the instability and progressive collapse (as seen in Figure 28)

The cumulative effect of the above-mentioned phenomena provides highly compelling reasons for the collapse of the WTC Towers. The study does not involve any uncertain assumptions with regards to the fire (as a large number of scenarios have been included, some producing collapses at relatively low temperatures). Furthermore, no gross assumptions of about structural behaviour have been made (such as the persistent claims about connection failures and resultant 'pancaking' of floors, without any supporting quantitative analysis). The analysis is very simple and should be reproducible with most proprietary finite element structural mechanics software capable of modelling non-linear large displacement behaviour.

\section{CONCLUSIONS}

The chief conclusions are:

1. The analysis presented points to a compelling fire induced collapse mechanism rather unique to the type of structure that the WTC Twin-Towers represented

2. This analysis also shows that the collapse is initiated principally by a stability mechanism as a result of geometry changes in the structure caused by thermal expansion effects

3. Furthermore it is quite possible that the geometric changes required to precipitate collapse could result from very low temperatures not high enough to induce significant reduction in the material properties

4. It can therefore be provisionally concluded that these buildings could have collapsed as a result of a major fire event. This is of course assuming that any of the active fire suppression systems would either fail or be unable to control the development of the fire. This is a normal assumption when designing fire protection for buildings

To achieve a firmer conclusion a 3D analysis would be necessary, also with a large range of reasonably realistic fire scenarios as carried out for this analysis. The current analysis clearly assumes that there is no support forthcoming from the directional orthogonal to the plane of the analysis. It is very likely, particularly for low temperatures that this additional support will delay failure and the the failing column will unload and the load will redistribute. This however could not carry on ad-infinitum and collapse would eventually occur. Furthermore dynamic effects have not been considered in this analysis, which could either add to the destabilising forces or delay them or both. A 3D dynamic analysis of this problem is the next logical step to take this investigation further.

\section{References}

[1] Behaviour of steel framed structures under fire conditions. Technical Report Main Report, DETR-PIT Project, School of Civil and Environmental Engineering, University of Edinburgh, 2000. available at www.civ.ed.ac.uk/research/fire/technicalreports.html. 
[2] A.S.Usmani, J.M.Rotter, S.Lamont, A.M.Sanad, and M.Gillie. Fundamental principles of structural behaviour under thermal effects. Fire Safety Journal, 36:721-744, 2001.

[3] Structural fire engineering investigation of Broadgate phase 8 fire. Technical report, Steel Construction Institute, Ascot, UK, 1991.

[4] Swinden Technology Centre British Steel plc. The behaviour of multi-storey steel framed buildings in fire. Technical report, British Steel plc (now CORUS), 1999. European joint research program report.

[5] A.M.Sanad, J.M.Rotter, A.S.Usmani, and M.O'Connor. Composite beam in buildings under fire. Fire Safety Journal, 35:165-188, 2000.

[6] M.Gillie, A.S.Usmani, and J.M.Rotter. A structural analysis of the first Cardington test. Journal of Constructional Steel Research, 57:581-601, 2001.

[7] M.Gillie, A.S.Usmani, and J.M.Rotter. A structural analysis of the Cardington British Steel Corner Test. Journal of Constructional Steel Research, 58:427-443, 2002.

[8] A.S.Usmani and S.Lamont. Key events in the structural response of a composite steel frame structure in fire. In Proceedings of the SiF'02, The Second International Workshop for Structures in Fire, pages 351-368, Christchurch, New Zealand, March 2002.

[9] A.S.Usmani and N.Cameron. Limit capacity of composite floor slabs in fire. Cement and Concrete Composites Journal, 36. In press.

[10] N.J.K.Cameron and A.S.Usmani. Analytical solutions for floor slabs in fire. In Proceedings of the SiF'02, The Second International Workshop for Structures in Fire, pages 115-126, Christchurch, New Zealand, March 2002.

[11] A.S.Usmani and N.J.K.Cameron. A new method to determine the ultimate load capacity of composite floors in fire. In Proceedings of ICASS'02, Third International Conference on Advances in Steel Structures, pages 1079-1088, Hong Kong, China, December 2002.

[12] Z.P.Bazant and Y.Zhou. Why did the World Trade Center collapse?-Simple analysis. Journal of Engineering Mechanics, ASCE, 128(1):2-6, 2002.

[13] World Trade Center Building Performance Study: Data collection, preliminary observations and recommendations. Technical Report FEMA 403, Federal Emergency Management Agency, Washington, DC, 2002.

[14] R.G.Rehm, W.M.Pitts, H.R.Baum, D.D.Evans, K.Prasad, K.B.McGrattan, and G.P.Forney. Initial Model for Fires in the World Trade Center. Technical report, NIST, USA, 2002.

[15] J.L.Torero, J.G.Quintiere, and T.Steinhaus. Fire Safety in High Rise Buildings: Lessons learned from the WTC. Dresden, Germany, October 2002. Jahresfachtagung der Vereingung zur Forderrung des Deutschen Brandschutzez e. V.

[16] J.G.Quintiere, M.diMarzo, and R.Becker. A suggested cause of the fire-induced collapse of the World Trade Towers. Fire Safety Journal, 37:707-716, 2002.

[17] S.P.Timoshenko and J.M.Gere. Theory of Elastic Stability. McGraw Hill Book Company, 1961.

[18] British Standards Institution. Eurocode 3, Design of steel and structures, 2001. 